\title{
Assessment of obesity, presumed and proven causes and prevention strategies: a review
}

\begin{abstract}
The obesity epidemic has been widespread in many countries, and has several adverse consequences. So many factors, some probable, others verified and documented, are known to contribute to the obesity problem in developed and developing countries. Nutritionists and other health professionals need to be skilled in understanding these various causes and their health implications. They should also be able to assess excessive body weight in clinical and other settings. Armed with this knowledge, health professionals should therefore be able to advise consumers and clients struggling with weight management on cost-effective preventive strategies to prevent or reduce incidence of obesity. In addition, nutritionists should be able to advise food manufacturers to make and market healthy food products. This paper will address the growing concern on obesity epidemic by reviewing the presumed and published or proven causes of obesity and the various methods for measurement of obesity. Strategies for preventing obesity will also be discussed. Such strategies would include lifestyle changes, physical activity, diet and behaviour modifications as well as reading food labels and proper food selection. Preventive strategies for obesity and overweight when properly implemented are very cost effective especially at persona and community levels and will ensure good health and wellness in many populations.
\end{abstract}

Volume 5 Issue | - 2016

\author{
Stella G Uzogara \\ Department of Public Health, Bureau of Family Health \& \\ Nutrition, USA
}

\begin{abstract}
Correspondence: Stella G Uzogara, Department of Public Health, Bureau of Family Health \& Nutrition, Commonwealth of Massachusetts, 250 Washington Street, Boston Massachusetts, 02108, USA, Tel $6176246 \mid 47,7812237893$

Email stellauzogara@gmail.com
\end{abstract} Received:September 06, 2016 | Published: September 30,
2016

Keywords: assessment, obesity, epidemic, overweight, presumed, proven causes, prevention, weight management, health \& wellness

Abbreviations: ACE , american council on exercise; BIA, bioelectric impedance analysis; BMI, body mass index; BMR, basal metabolic rate; CAT SCAN, computerized axial tomography scan; CDC, center for disease control and prevention; DASH, dietary approach to stop hypertension; DEXA, dual energy x-ray absorptiometry; DGA, dietary guidelines for americans; HC, hip circumference; HFCS, high fructose corn syrup; HP2020, healthy people 2020 guidelines; IOTF, international obesity task force; MRI, magnetic resonance imaging; NCHS, national center for health statistics; NGO, non governmental organizations; NHLBI, national heart lung blood institute; NLIS, nutritional landscape information systems of who; OECD, organization of economic cooperation and development; TLC, therapeutic lifestyle change diet for cholesterol; USA, united states of america; USDA, united states department of agriculture; WC, waist circumference; KG, kilogram; LB, pound; $\mathrm{M}$, meter; W, weight; $\mathrm{D}$, density; V, volume; WHO, world health organization; WHR, waist to hip ratio; $\mathrm{WHtR}$, waist to height ratio

\section{Introduction}

Obesity and overweight trends have reached epidemic proportions in many countries, ${ }^{1-8}$ and have serious health and socio-economic consequences. In addition, obesity has negative medical, psychological and quality of life consequences, drains health care resources and reduces life expectancy. The International Obesity Task Force (IOTF) projects that obesity rates worldwide would increase very significantly by 2025 unless appropriate intervention is taken. ${ }^{9}$ In the USA, between $2011 \& 2012$, the percent of US adults aged 20years and above who are obese was reported to be $35.1 \%$, while the percent of US adults who had excess body weight (overweight and obesity)in the same period was $69.0 \%$ according to published reports. ${ }^{2,10}$ Obesity and related chronic diseases are no longer a problem of affluent countries alone, as poor developing countries, middle income countries or countries undergoing economic transition, are also affected by the epidemic., ${ }^{4,6-8}$ Global, national and state public health agencies as well as their nutritionists, researchers and educators have raised awareness or taken immediate action to arrest the increasing weight trends and obesity in adults, the youth and children. ${ }^{11-16}$ Despite the high prevalence of obesity in many parts of the world, segments of populations (such as geriatric, very sick people, preschool children, pregnant \& lactating women) suffer from underweight. ${ }^{7,17-19}$ In some developing countries, various types of unhealthy weight such as obesity, overweight and underweight, can coexist concurrently in different segments of their populations. ${ }^{7,18-21}$ There are so many factors that cause or contribute to obesity. A previous paper had discussed obvious and hidden calories as causes of obesity. ${ }^{22}$ This paper will review various other causes of obesity, both probable and proven causes, and will discuss various methods of measurement of obesity in clinical, research, community or field settings. In particular, it will discuss strategies to prevent obesity and excessive weight gain to ensure health and wellness in many populations. A better understanding of the assessment and causes of obesity will lead to a concerted action to prevent and fight the obesity epidemic.

\section{Discussion}

\section{Methods of assessing obesity and overweight in adults}

Obesity can be determined by many methods, some of which are quite simple, while others are complex or sophisticated. These methods of assessment include the body mass index or BMI, other anthropometric methods, skin fold callipers that measures percent body fat and high technology or advanced methods. 


\section{The BMI method of assessing obesity/overweight}

Obesity and overweight are commonly estimated by a metric known as body mass index or BMI. The BMI is one of the anthropometric measurements used in clinical calculations. (In anthropometry, body weight, height, length, circumferences and thicknesses of parts of the body are measured and used to estimate body fat and general weight status such as normal weight, underweight overweight and obesity). The BMI is a measure of a person's weight relative to the person's height. This index is highly correlated with the amount of body fat, and is used to assess risk of diseases related to excess body fat, but it is not a direct measure of fat. High BMI correlates with obesity and higher health risks such as some cancers, cardiovascular diseases, diabetes, hypertension, stroke, sleep apnea, degenerative joint diseases, infertility, respiratory problems, skin problems, gall bladder disease and other conditions.

Scientifically, BMI is calculated in the metric system as body weight in kilograms $(\mathrm{Kg})$ divided by the person's height in meter squared (m2). $\left\{\right.$ Hence $\left.\mathrm{BMI}=\mathrm{kg} / \mathrm{m}^{2}\right\}$. In the imperial system of measurement, BMI is calculated as body weight in pounds (lb) divided by height in inches squared (in2) and the result is multiplied by the number, 703 , to get the BMI. $\{$ Hence BMI= $(\mathrm{lb} / \mathrm{in} 2) \times 703\}$. Total body weight includes non-lean body mass (storage fat and subcutaneous fat) and lean body mass (bone, muscle, organ, skin, fluid, non fat cells, \& nonfat tissues).

\section{BMI classifications}

Healthy weight: In most populations of the world, a person with healthy weight is regarded as one whose BMI value lies between 18.5 and 24.9. A BMI value higher than 25.0 predisposes a person to high fat accumulation and a higher risk of metabolic diseases such as metabolic syndrome, heart disease, diabetes, hypertension, stroke, hernia, sleep apnea, gall bladder disease, intestinal obstruction and certain cancers. It should however be noted that for some reasons, a few people with a BMI of 25.0 or greater are not predisposed to the above risk.

Overweight: An overweight person is someone whose BMI lies between 25.0 and 29.9; the overweight person is about $10 \%$ greater than expected ideal body weight; the person may eventually become obese if no intervention to reduce weight occurs. The term overweight is different from over fat. An over fat person is someone who has a higher percentage of body fat than is normal or healthy compared to the average person of same sex, age and gender. To determine over fat, a person's total body fat is measured and compared to expected percent fat by age, read off a chart. If a man's percentage fatness is $20 \%$ greater than expected total body fat, or if a woman is $30 \%$ greater than expected body fat, the person is over fat. It should also be noted that a person can be overweight without being over fat and vice versa, but a man with body fat equal to or greater than $25 \%$, or a woman with body fat equal to or greater than $32 \%$ may be both over fat and obese according to some reports. ${ }^{23}$ The ratio of body fat to lean tissue is a better determinant of health and fitness than weight alone that is measured on a bath scale or other methods. Lean tissue however decreases due to inactivity and ageing. Ageing leads to decrease in basal metabolic rate (BMR) and decreased lean tissue but increase in body fat. Physical activity increases BMR and also increases lean tissue and tends to slow the ageing process. This is why participation in various physical activities, exercise and fitness programs as well as good nutrition is necessary for better ageing.
Essential body fat: Fat is an important body component with several functions. It should be noted that not all fat is bad. Certain fat known as 'essential body fat' is necessary for adequate body physiology and for good health and such fat is stored in muscles, organs, bones and central nervous system. Men require about $2-4 \%$ essential fat while women require $8-12 \%$ essential fat. Essential fat is higher in women to enable them maintain hormonal and reproductive processes and to stay in good health. The rest of the body fat that is not needed for vital functions is non essential fat, which also have other purposes in the body such as insulation, serving as protective padding, storing excess energy for use during starvation, etc. Non essential fat is stored throughout the body around organs, inside body cavities like abdomen, and even under the skin. A regular/average man may have $12-20 \%$ total body fat while a regular/average woman may have $18-25 \%$ total body fat according to a report by the American Council on Exercise. ${ }^{24}$ It is best to keep the level of non essential fat at a healthy level through weight loss or weight maintenance to prevent overweight and obesity.

Underweight: An underweight person is one whose BMI is less than 18.5. If the underweight condition is sustained for a long time, the person may be at risk of developing serious conditions and may be prone to falls, poor stamina, anaemia, malnutrition, poor wound healing and various illnesses. ${ }^{19}$

Obesity: A person living with obesity is one whose BMI value is 30.0 or higher. Obesity has 3 sub-classes based on the severity of the problem, class 1 , or mild obesity (BMI at 30.0-34.9), class II or moderate obesity(BMI at 35.0-39.9) \& class III or extreme/morbid obesity(BMI at 40.0 and above) as shown for the general populations in Table 1a. Obesity has many medical and quality of life consequences and health risks. The general classification of BMI values and weight status has been published in literature..$^{25}$

Table Ia General BMI classification by weight status for general population**

\begin{tabular}{ll}
\hline BMI class & Weight status \\
\hline$<18.5$ & Underweight \\
$18.5-24.9$ & Normal weight (or healthy weight) \\
$25.0-29.9$ & Overweight \\
$30.0-34.9$ & Obesity class I \\
$35.0-39.9$ & Obesity class II \\
$40.0-40+$ & Obesity class III (morbid obesity \\
\hline
\end{tabular}

\section{Source: Jensen et al. ${ }^{26 * *}$ except for Asians.}

The BMI value cut-offs: The BMI cut offs for healthy weight, overweight and obesity statuses are different for Asian populations. ${ }^{26,27}$ Asians have a higher tendency to develop metabolic syndrome, so their BMI cut-off for obesity is revised downwards to less than 30.0 according to published reports. ${ }^{26}$ One study states that BMI for Asians (especially Japanese) is set at 25.0, while BMI of 23.0 to 24.9 is designated as overweight, and BMI of 30.0 is designated as obesity class II for Japanese or other Asians. ${ }^{26}$ Other studies have put BMI of 27 or higher as obesity cut off for Asians and Asian Americans. ${ }^{27,28}$ Thus a BMI considered normal or low for a non Asian may place Asians at risk. (Table 1b), modified from the Joslin Diabetes Center ${ }^{29}$ compares Asian and non- Asian BMI cut offs. 
Table I b Asian and non- Asian BMI cut offs.

\begin{tabular}{|c|c|c|c|}
\hline $\begin{array}{l}\text { BMI cut-off } \\
\text { for Asians } \\
\text { and Asian } \\
\text { Americans }\end{array}$ & Weight status & $\begin{array}{l}\text { NIH BMI } \\
\text { cut-off for } \\
\text { non Asians }\end{array}$ & Consequences \\
\hline$<18.5$ & Underweight & $<18.5$ & $\begin{array}{l}\text { An unhealthy weight status; Risk of developing health problems, falls, poor stamina, anemia, } \\
\text { malnutrition, poor wound healing \& various illnesses; Requires good nutrition and activity to } \\
\text { maintain healthy weight. }\end{array}$ \\
\hline $18.5-22.9$ & $\begin{array}{l}\text { Healthy weight } \\
\text { range }\end{array}$ & $18.5-24.9$ & $\begin{array}{l}\text { Weight in normal range, but should continue to monitor diet and activity; engage in regular } \\
\text { physical activity and good nutrition to maintain the healthy weight. }\end{array}$ \\
\hline $23-26.9$ & Overweight* & $25-29.9$ & $\begin{array}{l}\text { An unhealthy weight status; risk of developing chronic disease (e.g. heart disease, diabetes) if no } \\
\text { sustained intervention to maintain healthy weight is provided. Test for diabetes in overweight } \\
\text { Asians. }{ }^{27} \text { Advice from health professional recommended. }\end{array}$ \\
\hline$\geq 27$ & Obese & $\geq 30.0$ & $\begin{array}{l}\text { An unhealthy weight status; risk of developing chronic disease (heart disease, diabetes) if no } \\
\text { sustained intervention to maintain healthy weight is provided. Test for diabetes in all groups. } \\
\text { Advice from health professional recommended. }{ }^{27}\end{array}$ \\
\hline
\end{tabular}

*Modified from Joslin Diabetes Center BMI chart. ${ }^{29}$

BMI limitations: Although high BMI usually correlates with high body fat, there are some exceptions in that some high BMI levels can be observed in situations not involving fatness, while low BMI values can be observed in people who carry ample amount of fat tissue.

For example, athletes and weight lifters, people with increase in muscle and bone mass due to body building, or people born naturally big as well as people with edema or ascites, have high body weight and high BMI values but these conditions do not reflect fatness.

Body builders have increased muscle and bone mass through body building, weight lifting and rigorous walk outs and this increases their total muscle mass, bone strength and body weight which can result in high BMI. Similarly, high BMI values are observed in people who are born big naturally because of genetics. Such people naturally have heavy bones and big muscles and consequently high body weight.

The BMI value is also high in people living with edema and ascites. Edema is abnormal accumulation of fluid in various parts of the body especially at the extremities such as hands, arms and wrists or legs, feet and ankles. Ascites is an abnormal condition in which serous fluid accumulates mostly in the peritoneum or abdominal cavity and other body regions. Fluid accumulation can arise from different causes such as liver disease, cancer, bacterial peritonitis, alcohol abuse, congestive heart failure, kidney failure, salt and water retention or obstruction of lymphatic system as in elephantiasis. Conditions that are accompanied by excess body fluid accumulation and inflammation tend to increase body weight. The increased body weight and consequent high BMI values in all these conditions can be misleading and might be erroneously interpreted as fat.

Similarly very low BMI in frail elderly people can also be misleading. The low BMI observed in older adults may be due to the fact that they have lost muscle mass and/ or height which affects their BMI readings. Some elderly people with low BMI may still accumulate fat and display large waist circumference which increases risk of diseases like diabetes that accompany body fat. BMI is also has limitations in growing children, some athletes and anorectics.

Thus BMI method of estimating obesity is therefore not perfect and has general limitations; it does not distinguish between lean tissue, fat or bone mass. The BMI calculation involves total body weight; total body weight is a metric that consists of lean and non-lean tissue. Lean tissue comprises bone, muscle, organs, skin \& fluids, while and non- lean tissue consists of body fat (i.e. storage fat and peripheral fat). Storage fat is also known as adipose tissue, while peripheral fat is also known as subcutaneous (under-the- skin) fat. Body fat is expressed as a percent of total body weight (i.e. body fat is calculated as total body fat divided by total body weight, and the result is multiplied by 100).

Another limitation of BMI is that it also does not indicate the location of the excess fat. Some fat may be stored inside the organs or underneath the skin, some are concentrated in the upper body and abdomen leading to both high BMI and large waist circumference, while other fat are concentrated in lower body and these locations have different consequences for obesity and metabolic risk.

The BMI value does not account for racial, gender or age differences. BMI classifications are different for Asians compared to Caucasians and other ethnic groups. Asians with BMI considered low for whites or white Americans may still be at risk of abdominal obesity, diabetes, hypertension and heart disease, despite their apparent low BMI readings..$^{27}$ Despite its limitations, $\mathrm{BMI}$ is widely used in clinical and community settings and is quite simple and inexpensive.

BMI, fat distribution and body shape: High BMI can affect body shape, obesity type and consequences. If the main location of body fat stores is concentrated in the upper body, the obesity is called upper body obesity or apple shape obesity, while excess fat concentrated mainly in the lower body is called lower body obesity or pear shape obesity, as described in a previous report. ${ }^{22}$ Apple shape obesity poses a greater metabolic risk than pear shape obesity ${ }^{30}$ showing that regional distribution of excess body fat affects both mortality and morbidity.

\section{Other anthropometric measurements of obesity in adults}

Besides BMI, other anthropometric methods of estimating obesity are useful in clinical or community settings (Table 2). Such methods include waist circumference, hip circumference, waist-to-hip ratio, waist-to-height ratio, skin fold thickness, body density and body volume and these methods have been documented in literature. ${ }^{18,29-31}$ However, the anthropometric methods such as BMI, waist circumference, waist- to-hip or waist-to-height ratios, are the most commonly used in the field or community setting as they are quite inexpensive and simpler to use though they are less accurate than the high tech methods used in hospitals or research institutions (Table 3). 
Table 2 Simple and low tech methods of determining obesity in adults in clinics or community settings

\begin{tabular}{|c|c|c|}
\hline Method & Description & Obesity indicator \\
\hline $\begin{array}{l}\text { BMI (metric system } \\
\text { measurements) }\end{array}$ & $\begin{array}{l}\text { Body weight in kilogram }(\mathrm{kg}) \text { divided by height in meter } \\
\text { squared }\left(\mathrm{m}^{2}\right) .\left(\mathrm{BMl}=\mathrm{kg} / \mathrm{m}^{2}\right)\end{array}$ & $\begin{array}{l}\text { BMI=> } 30 \text { is indicative of obesity } \\
\text { BMI=> } 40 \text { is indicative morbid obesity; } \\
\text { High } \mathrm{BMI} \text { is a good predictor of high risk of chronic } \\
\text { disease(heart disease \& diabetes) and premature death } \\
\text { BMI gives an estimate of fat, but has has limited accuracy in } \\
\text { some population groups. It is an inexpensive method. }\end{array}$ \\
\hline $\begin{array}{l}\text { BMI (Imperial system } \\
\text { measurements) }\end{array}$ & $\begin{array}{l}\text { Body weight in pounds }(\mathrm{lb}) \text { divided by height in inches } \\
\text { squared }\left(\mathrm{in}^{2}\right) \text {, multiplied by } 703 \text {. } \\
\left(\mathrm{BMI}=703 \times\left(\mathrm{lb} / \mathrm{in}^{2}\right)\right.\end{array}$ & Same as BMI in metric system above. \\
\hline $\begin{array}{l}\text { Waist Circumference } \\
\text { (WC) }\end{array}$ & $\begin{array}{l}\text { WC is distance round the waist through the belly button, } \\
\text { measured using a tape measure. }\end{array}$ & $\begin{array}{l}\text { WC }>35 \text { inches for women indicates obesity; } \\
\text { WC }>31.5 \text { inches for Asian women indicates obesity; } \\
\text { WC }<35 \text { inches for women is overweight } \\
\text { WC }>40 \text { inches for men is obese; } \\
\text { WC }>35.5 \text { inches for Asian men indicates obesity; } \\
\text { WC }<40 \text { inches for men is overweight; } \\
\text { WC is good for determining abdominal or apple shape } \\
\text { obesity. }\end{array}$ \\
\hline $\begin{array}{l}\text { Hip circumference } \\
(\mathrm{HC})\end{array}$ & $\begin{array}{l}\mathrm{HC} \text { is the distance round the hip through the widest part } \\
\text { of buttocks, using a tape measure. } \\
\text { The WC \& HC are used to calculate WHR. }\end{array}$ & \\
\hline $\begin{array}{l}\text { Waist- to-Hip } \\
\text { Ratio(WHR) }\end{array}$ & $\begin{array}{l}\text { WHR=Waist circumference divided by } \mathrm{Hip} \\
\text { circumference, measured in same units. }(\mathrm{WHR}=\mathrm{WC} / \mathrm{HC})\end{array}$ & $\begin{array}{l}\text { WHR }>0.8 \text { for women indicates obesity; } \\
\text { WHR }>0.9 \text { for men indicates obesity } \\
\text { WHR good for determining abdominal obesity, apple shape or } \\
\text { android obesity } \\
\text {-Has limited accuracy. }\end{array}$ \\
\hline $\begin{array}{l}\text { Waist-to-Height Ratio } \\
\text { (WHtR) }\end{array}$ & $\begin{array}{l}\text { WHtR }=\text { Waist circumference }(\mathrm{WC}) \text { divided by Height }(\mathrm{Ht}) \text {, } \\
\text { measured in same units. }(\mathrm{WH} t \mathrm{R}=\mathrm{WC} / \mathrm{Ht})\end{array}$ & $\begin{array}{l}\text { WHtR }>0.5 \text { for man or woman is indicative of obesity; } \\
W H t R<0.5 \text { is acceptable for healthy weight; } \\
W H t R \text { is a simpler method than BMI. }{ }^{30-34} \\
\text { Best to keep waist circumference at less than half of person's } \\
\text { height to increase life expectancy. }{ }^{32-34}\end{array}$ \\
\hline $\begin{array}{l}\text { Skin fold fat thickness } \\
\text { (Pinch test) }\end{array}$ & $\begin{array}{l}\text { The pinch test uses skin fold calipers to measure } \\
\text { subcutaneous fat in a pinched skin in specific areas of } \\
\text { body, e.g. biceps, triceps muscle in upper arm, trunk, } \\
\text { thigh and shoulder blade. Fat thicknesses in centimeters } \\
\text { are computed for } 4 \text { surfaces and plugged into predictive } \\
\text { equations to calculate percent body fat. Percent body } \\
\text { fat can also be read off a chart of skin fold thickness in } \\
\text { millimeters by age and gender }{ }^{29,40}\end{array}$ & $\begin{array}{l}\text { According to American Council on Exercise or ACE: }{ }^{29,40} \text { For } \\
\text { males, Body fat } \% \text { : } \\
\text { I4- I } 7 \% \text { is acceptable or fit, } \\
18 \text { to } 24 \% \text { is overweight, } \\
25 \% \text { and higher is obese; According to ACE: } 29,40 \\
\text { For females, Body fat } \% \\
21-24 \% \text { is acceptable or fit, } \\
25 \text { to } 31 \% \text { is overweight, } \\
32 \% \text { and higher is obese: }\end{array}$ \\
\hline
\end{tabular}

Waist Circumference (WC): Waist circumference is distance round the waist through the belly button and correlates well with level of abdominal fat. A waist circumference greater than 35 inches (or $>88 \mathrm{~cm}$ ) in women or greater than 40inches (or $>102 \mathrm{~cm}$ ) in men is indicative of obesity. For Asians, a waist circumference greater than 31.5 inches (or $>80 \mathrm{~cm}$ ) in women or greater than 35.5 inches (or $>90 \mathrm{~cm}$ ) in men is indicative of obesity.

Hip circumference (HC): Hip circumference is distance round the hip through the widest part of the buttocks. Together with WC, it can contribute in estimating obesity in an individual. The WC \& HC are used to calculate waist-to-hip ratio.

Waist-to-hip ratio (WHR): Waist-to-hip ratio is ratio of waist circumference to hip circumference, measured in the same units $(\mathrm{WHR}=\mathrm{WC} / \mathrm{HC})$. The WHR greater than 0.8 in women or greater than 0.9 in men is indicative of overweight and/or obesity. The greater the WHR in a person, the more obese the person is.

Waist-to-height ratio (WHtR): The WHtR is ratio of waist circumference to a person's height, measured in the same units. The WHtR greater than 0.50 is indicative of overweight and obesity. The greater the WHtR, the more obese the person is and the greater the metabolic risk. ${ }^{32-34} \mathrm{~A}$ recent study suggests keeping the WHtR bellow 0.50 to increase longevity and life expectancy. ${ }^{30}$ High values for WC, WHR and WHtR correlate positively with high rates of obesity, overweight, abdominal fat and high risk of metabolic diseases as earlier described. ${ }^{19}$

Skin fold fat thickness (pinch test): A pinch test determines fat using skin fold callipers. This is a more accurate way of assessing body fat compared to other anthropometric methods such as BMI as the pinch 
test measures body fat thickness directly. However pinch test is less accurate than the precise high technology methods used in research. In the pinch test, body fat can be estimated with skin fold body callipers that determines fat in a pinched skin over several body surfaces such as trunk, chest, abdomen, thigh, supra-ileum and shoulder blade as well as biceps or triceps muscle in the upper arm. Fat thicknesses in centimetre are plugged into predictive equations to calculate percent body fat. Alternatively, sum of the skin fold fat thicknesses in millimetre together with age can also be used to estimate total body fat using appropriate charts for percent fat estimates for men or women. In the 1980s, Jackson and Pollock developed tables that relate body fat, age and skin fold thicknesses ${ }^{35}$ and many researchers have validated or improved this method of estimating body fat. ${ }^{36,37}$ In one such method, to determine total body fat for women, sum of skin fold thickness in triceps, thigh and supra-ileum are used, while for men, sum of skin fold thicknesses in the chest, abdomen and thigh are used. The sums of body thicknesses in millimetres are cross-referenced with age group to estimate percent body fat from the chart. ${ }^{32,38}$ However this method of determining fat may not be good for some people with

Table 3 Advanced and high tech methods of determining obesity in adults autism or other intellectual disability because of noncompliance of subjects during skin fold measurements; such non-compliance can results in inaccurate and imprecise results. ${ }^{39}$

\section{Advanced and high technology methods of determining obesity}

In research and clinical settings, the most accurate but quite expensive high tech methods of estimating obesity are used. These include bioelectric impedance analysis (BIA), Dual Energy X-ray Absorptiometry (DEXA), isotope labeled water, near-infrared interactance, Computerized Axial Tomography (CT) scan, Magnetic Resonance Imaging (MRI), densitometry, air displacement plethysmography and ultrasound technology. Some of the high tech methods used in research for estimating obesity can measure body water, total body fat mass, tissue and organ fat, fat-free mass, lean body mass and, in some cases, bone mineral density. However most of the high tech methods require special skills to operate and are also expensive, therefore not available in the field or community settings (Table 3).

\begin{tabular}{|c|c|c|}
\hline Method & Description & Obesity indicator \\
\hline $\begin{array}{l}\text { Bioelectric Impedance } \\
\text { Analysis (BIA) }\end{array}$ & $\begin{array}{l}\text { Special electrical equipment passes electric current through body, fat , body water and } \\
\text { lean body mass; generated reading is used in equation to calculate total body fat and } \\
\text { fat free mass }\end{array}$ & $\begin{array}{l}\text { High fat mass is indicative of } \\
\text { obesity }\end{array}$ \\
\hline $\begin{array}{l}\text { Dual Energy X-ray } \\
\text { Absorptiometry (DEXA) }\end{array}$ & $\begin{array}{l}\text { The method uses } x \text {-ray beams to determine fat mass, fat free mass and bone mineral } \\
\text { density. }\end{array}$ & $\begin{array}{l}\text { High fat mass is indicative of } \\
\text { obesity }\end{array}$ \\
\hline \multicolumn{3}{|l|}{ Computerized Axial } \\
\hline $\begin{array}{l}\text { Tomography Scan (CAT } \\
\text { scan) \& Magnetic Resonance } \\
\text { Imaging (MRI), }\end{array}$ & $\begin{array}{l}\text { These methods use electrical and magnetic energy to determine fat mass (in whole } \\
\text { body, tissues or organs); can also determine bone mass and lean body mass. }\end{array}$ & $\begin{array}{l}\text { High fat mass is indicative of } \\
\text { obesity }\end{array}$ \\
\hline Ultra sound & The method uses ultrasound to determine body fat mass and fat free mass & $\begin{array}{l}\text { High fat mass is indicative of } \\
\text { obesity }\end{array}$ \\
\hline Near -Infrared Interactance & $\begin{array}{l}\text { The method uses infrared rays to determine body fat mass and fat free mass. A beam } \\
\text { of infrared rays is passed through the dominant arm and the energy in the beam can } \\
\text { be absorbed, reflected or transmitted depending on fat mass and fat-free mass. }\end{array}$ & $\begin{array}{l}\text { Suitable for very sick children } \\
\text { whose body fat cannot be } \\
\text { determined by skin fold caliper } \\
\text { methods. }{ }^{39}\end{array}$ \\
\hline Body Density & $\begin{array}{l}\text { A person is first weighed in air, then body volume is determined by water } \\
\text { displacement of the submerged body in a calibrated tank. Body density }(d) \text { is body } \\
\text { weight(w) divided by body volume }(v) .[d=w / v]\end{array}$ & $\begin{array}{l}\text { Less dense body is high in fat, } \\
\text { has high buoyancy and floats. }\end{array}$ \\
\hline Body Volume & By air displacement in an enclosed chamber (e.g. the Bod Pod) & $\begin{array}{l}\text { Higher body volume leads } \\
\text { to lower density and hence } \\
\text { indicative of more fat. }\end{array}$ \\
\hline Isotope labeled water & $\begin{array}{l}\text { In this method, subject drinks isotope labeled water, donates body fluids and isotope } \\
\text { level determined and used to calculate total body water, fat mass and fat free mass. }\end{array}$ & $\begin{array}{l}\text { High level of fat mass is } \\
\text { indicative of obesity }\end{array}$ \\
\hline
\end{tabular}

Sources: ${ }^{18,27-36}$

In BIA, a machine sends small safe electric current through the body and measures resistance. Tissues with high fat mass show higher resistance than those with non-fat mass.

In DEXA, x-ray beams are passed through body; the rays pass through different tissues at different rates which are used to determine fat and fat- free mass as well as bone mineral density.

In Near Infrared techniques, near infrared rays are passed through body; the rays pass through different tissues at different rates which are used to determine fat mass and fat- free mass. The technique is suitable for very sick children and people who could not comply with the pinch test. ${ }^{39}$
In Isotope Labelling technique, isotope labelled water is given to the subject to drink, and body fluid samples are donated by the subject afterwards. The donated body fluid (containing labelled isotope) is used to determine total body water, fat mass and fat free mass through isotope counting.

The CT \& MRI methods are imaging techniques that accurately measure fat mass and lean body mass, including bone, muscle, whole organs and tissues.

In densitometry or underwater weighing, body volume and body density are determined. The subject is first weighed in air and later weighed submerged in a calibrated tank. The body volume is 
determined by water displacement. Using prescribed formulae, the density and body fat are calculated. Body density is body weight divided by body volume. Low density indicates high fat. A body that is high in fat will float. The snag with this method is that it is time consuming and is not usually used in community settings though it is appropriate for research purposes because of its good level of accuracy compared to other anthropometric methods.

Air Displacement Plethysmography involves a special enclosure or air chamber. First the pressure in the empty chamber is determined. Then a subject wearing a special bathing suit is seated in the enclosed chamber and the air pressure in the occupied chamber is determined as subject is weighed in air inside the chamber. The air pressure difference between the empty chamber and occupied chamber is used to determine body volume and consequently body density. A good example of this technique is the BodPod, an efficient small machine that determines body weight and body volume and calculates body composition, showing ratio of lean tissue to fat tissue. This air displacement method is almost similar to underwater weighing except that in this method, body volume is determined by air displacement in the chamber whereas in underwater weighing, body volume is determined by water displacement in a calibrated tank.

Measurement of obesity and overweight in children: Obesity and overweight are assessed in children using the CDC or the WHO growth charts in both clinical and community settings (Table 4).

Table 4 Measurement of growth, obesity and overweight in children by anthropometric measurements

\begin{tabular}{lll}
\hline Height/weight indicator & $\begin{array}{l}\text { Children aged < 2years (2006 WHO } \\
\text { growth charts) }\end{array}$ & $\begin{array}{l}\text { Children aged 2years and older (2000 CDC } \\
\text { growth charts) }\end{array}$ \\
\hline Short stature & $<2.3^{\text {rd }}$ percentile length-for-age & $<5^{\text {th }}$ percentile height-for-age \\
Underweight & $<2.3^{\text {rd }}$ percentile weight-for-length & $<5^{\text {th }}$ percentile BMI-for-age \\
High weight-for-length (children aged $<2$ years) & $>97.7^{\text {th }}$ percentile weight-for-length
\end{tabular}

Overweight (children aged 2years and older)

$85^{\text {th }}$ percentile to $<95^{\text {th }}$ percentile BMI-for-age

Sources: WHO CHILD growth standards. ${ }^{41,43,44}$

Obesity and overweight determination in children aged two years or more: To determine obesity in children (age 2 to 20years), the gender specific BMI-for-age percentile growth chart from the $\mathrm{CDC}$ is used. ${ }^{40}$ According to the gender-specific CDC growth chart percentiles developed in the year 2000 for children 2 years of age and older, obesity is defined as BMI-for-age greater than or equal to the 95th percentile; overweight is defined as BMI-for-age greater than or equal to the $85^{\text {th }}$ percentile but less than the 95 th percentile. ${ }^{41}$

Obesity/overweight determination in children aged less than two years: For children aged less than 2years, the World Health Organization (WHO) child growth chart is used to determine excess weight. According to the WHO growth chart percentiles developed in $2006^{42}$ for children less than 2 years of age, high weight-for-length percentile (erroneously labeled as "Obese") is defined as weight-forlength percentile greater than or equal to the 97.7 th percentile.

Children aged less than two years should not be categorized as obese, despite the "obese" label sometimes erroneously used by some people for such children. Rather, such children should be categorized as overweight, or as having excessive weight-for-height or high weight-for-length at the 97.7th percentile, based on the WHO 2006 growth chart. ${ }^{43}$ The CDC and WHO child growth charts have been compared and small differences in values of the growth indicators were observed between these growth charts. ${ }^{44}$

\section{Causes of obesity}

So many factors contribute to obesity and these include excessive caloric intake (from caloric macronutrients-fats, carbohydrates, proteins, alcohol), decrease caloric expenditure (through inactivity, lack of exercise or slow metabolism), fat distribution, body shape and other factors. Fat distribution (visceral, subcutaneous and intra-muscular fat) also contributes to body shape. Visceral fat is body fat stored in abdomen and around visceral organs. Subcutaneous or peripheral fat is body fat stored just underneath the skin while intramuscular fat is the body fat stored in between the skeletal muscles. Visceral fat accumulation increases the risk for cardiovascular diseases. ${ }^{28}$
Environmental factors and genetics influence body fat distribution but genetics appears to have a greater role in fat distribution while diet and exercise have more effect on total body fat content. ${ }^{45}$ There are so many causes of obesity, some of which are based on peoples' perception, the so called probable or presumed causes, while others are based on established facts that were published in literature.

Presumed causes of obesity and overweight: An informal interview of gym clients during a nutrition practicum by the author, on presumed causes of obesity and overweight, was conducted at a local gym and client responses revealed their perceptions on obesity. The responses showed that most of these gym clients were making strong efforts to control their weights by working out, exercising regularly, eating healthy foods and following proper lifestyle habits but they were not getting corresponding good results on their weight management. Some respondents gave different reasons for their perceived or presumed causes of their excess weight (Table 5). Others admitted to diligently counting calories and making efforts to maintain a healthy weight. Many of the gym clients admitted that they came to the gyms about 4 to 6 days a week to remain fit. Others claimed they registered concurrently in both the local gym and some other weight loss programs in their towns in an effort to maintain a healthy weight. Some of them reported that they scrutinized every piece of food that entered their mouths to ensure they did not overeat or gain excess weight. It is ironic that despite all their efforts at weight reduction or weight management, excessive body weight still persisted in many of these people. Perhaps some other factors such as hidden calories or other issues were causing or contributing to the excessive weight gain. $^{22}$

From responses given by this group of gym attendants, it appears that some activities were perceived as contributing to their weight gain and blamed as the cause of their overweight and obesity (Table 5 ). These causes of weight gain and obesity that were based on the respondents perception included skipping meals and later consuming excess amount of food to make up for the skipped meals; increasing portion sizes of consumed foods either as 'super-sized' meals, or 'all 
you can eat' buffets; sometimes over-indulgence on free foods, free snacks, taste samples, party foods and /or free drinks served during happy hours were blamed. Some respondents presumed that that going on frequent vacations since retirement, or going for second and third helpings of delicious meals caused weight gain; others especially housewives said that sitting down too much watching daytime soap

Table 5 Presumed or perceived causes of obesity and weight gain: Responses given by gym clients in response to a question -"In your opinion, what do you think makes you gain weight?' operas caused their problem; some felt that late night snacking, late night dinner or eating cold foods made them gain weight. Others said that going to bed on a full stomach, or eating a few minutes just before bed time as well as mindless eating possibly contributed to their weight gain.

\section{Presumed causes of obesity and overweight}

Skipping meals and later consuming excess food to make up skipped meals

Eating out in restaurants

Increased food portion sizes at home or restaurants

Indulging in 'supersized' meals, 'king size' or 'queen size' meals, or big portion sized meals

Buffets, or 'all you can eat' offerings in Chinese restaurants or fast foods joints

Over indulgence on light refreshments at work meetings or parties

Free snacks \& foods, free drinks served during happy hours or in test kitchens

Going for second ,third or even fourth helpings of delicious foods and pastries; -uncontrolled food cravings

Late night snacking, late dinners, going to bed immediately after dinner

Lack of sleep and eating to induce sleep

Eating comfort foods to deal with stress, no relaxation,

Eating out regularly at fast food or traditional restaurants.

Too busy to eat healthy foods that take much time to prepare.

Stress at work, eating to reduce stress

Baby fat gained during pregnancy that never went away; Frequent pregnancies

Eating good tasting and inexpensive foods

Cooking \& Sampling food advertised or seen on TV, food channels \& food network

Cultural and ethnic foods that are delicious but fattening

Frequent travels, vacations \& eating out; indulging in special foods while on vacations

Frequent 'light' refreshments that are heavy in calories
Frequent consumption of soft drinks (sodas) instead of water

Inviting friends over and cooking to please them; too much entertainment of guests and eating when not hungry;

Regular consumption of rich creamy coffees, sugar flavored teas, sweet beverages

Binge eating, nibbling foods all the time, over-eating, impulsive eating

Quit smoking but gained weight

Not exercising ;

inconsistent with exercise plan

Soothing my sweet tooth with candies, cookies, sweets, chocolates and flavored pastries

Drinking alcoholic beverages like beer, wine and liquors regularly;

-uncontrolled alcohol cravings

Eating more than 3 big meals in one day; not feeling satisfied even after eating.

Becoming a stay-at-home mom to care for my family

Making sure all left over foods are consumed instead of throwing them away; holiday feasting.

Fried foods, creamy pastries all the time

Reading food labels afterwards instead of before consuming the culprit food.

Quitting my job, staying at home,

Eating too much while breastfeeding;

Feeling hungry all the time while breastfeeding

Difficulty avoiding readily available good food, holiday foods, party foods.

Not drinking water or milk but drinking sweet beverages regularly;

Eating cold foods and beverages

Not bothering to check body weight, not using the bath scale for several months, not looking in the mirror to gauge body shape for several months.

Staying indoors all through winter and eating to keep warm; Ordering takeout meals from pizzerias and coffee shops.

Sitting down for a long time watching too many daytime soap operas, television or game shows or using the computers and internet all the time.
Some respondents claimed that they usually ate while working night shifts, the so called 'grave-yard shift' and believed that night shift foods caused their weight problems. Others said they formed the habit of regularly drinking alcohol along with their dinners which could be a factor in their weight gain. Some blamed the extra weight on too much entertainment and inviting friends and family over to their homes and cooking all the time. Others blamed the excess weight on eating out at restaurants instead of cooking at home. Some restaurant foods are claimed to be tasty but laden with high fat, salt and sugar. Some gym clients implicated stress and consumption of 
comfort foods as possible factors in their obesity. The responses to perceived or presumed causes of weight gain are not surprising as many of the reasons given by the respondents have also been published in literature as shown in Table 6-11.

Table 6 Possible diet related factors that cause obesity and overweight as published in literature

\begin{tabular}{ll}
\hline Possible Dietary \& Related factors that Cause Obesity/Overweight & References \\
\hline Food portion sizes; increased food consumption & $47-49$ \\
High intake of total fat, saturated fat and trans fat & 50,5 I \\
Fast food/Fried foods, & $52-55$ \\
Junk food & $56-57$ \\
-Soft drinks (sodas and sweetened beverages); & $57-61$ \\
-high caloric drinks, (sweetened \& caffeinated beverages, juices, sugary drinks, juice blends); \\
-Energy drinks & 62 \\
Alcoholic drinks & $56,62,63$ \\
Overeating, binge eating, mindless eating and excessive snacking & $52,56,62,63$ \\
Consumption of High fructose corn syrup and artificial sweeteners & 67 \\
Insufficient dietary calcium intake & 68,69 \\
Low intake of fiber , and Low intake of fruits and vegetables in foods & $70-74,78$ \\
Not breastfeeding or short breastfeeding duration ; formula feeding instead of breastfeeding & $79-82$ \\
Intestinal microbes & $83-87$ \\
Antibiotics in human foods &
\end{tabular}

Table 7 Activity related factors as possible causes of obesity and overweight published in literature

\begin{tabular}{lc}
\hline Activity factors as causes of obesity & References \\
\hline Physical Inactivity & $88-90$ \\
Lack of exercise or infrequent exercise & $89,91-93$ \\
Sedentary activities \& too much sitting time & 93,94 \\
Prolonged screen time- (TV, computer, video games, internet, social media use by adults and children) & 95,96 \\
Occupational hazards -prolonged sitting jobs by taxi drivers, as well as truck, bus drivers and fire firefighters & 97 \\
\hline
\end{tabular}

Table 8 Possible Lifestyle \& Behavioral factors as Causes of Obesity and overweight published in literature

\begin{tabular}{|c|c|c|c|}
\hline Lifestyle \& behavioral causes of obesityl & References & Environmental causes of obesity \& overweight & References \\
\hline Sedentary lifestyle & 97 & Food environment & $109-111$ \\
\hline $\begin{array}{l}\text { Eating out frequently in traditional and fast food } \\
\text { restaurants }\end{array}$ & 98 & $\begin{array}{l}\text { Unsafe recreation and living areas } \\
\text { Unwholesome foods }\end{array}$ & $\begin{array}{l}112-115 \\
116\end{array}$ \\
\hline Frequent vacations - dinning \& wining & 99 & Low ambient temperature & $117-119$ \\
\hline Insufficient sleep or lack of sleep & 100 & Food deserts & $|20,12|$ \\
\hline $\begin{array}{l}\text { Staying at home to watch movies, soap operas, daytime } \\
\text { TV shows etc }\end{array}$ & 101,102 & Obesogenic chemicals such as endocrine disruptors & \\
\hline $\begin{array}{l}\text { Shift work/night shift/unusual work schedule } \\
\text { Eating pattern \& eating behavior }\end{array}$ & $\begin{array}{l}103 \\
92,104,105\end{array}$ & $\begin{array}{l}\text { (Bisphenol A, phthalates, atrazine, organotins and } \\
\text { perfluorooctanoic acid) }\end{array}$ & 122,123 \\
\hline Discontinuation of smoking & $106,107,108$ & Obesogenic foods & 118 \\
\hline
\end{tabular}

Table 9 Possible environmental causes of obesity and overweight published in literature 
Table I 0 Possible medical and health causes of obesity and overweight published in literature

\begin{tabular}{|c|c|}
\hline Causes of obesity & References \\
\hline \multicolumn{2}{|l|}{ Hormonal malfunctions } \\
\hline -Hypothyroidism & 125 \\
\hline -Prader Willie syndrome & 126 \\
\hline$-\mathrm{PCOS}$ & $127-129$ \\
\hline -Cushing's syndrome & 130 \\
\hline -Other endocrine diseases & $|3|$ \\
\hline \multicolumn{2}{|l|}{ Mental health problems } \\
\hline -depression & $132-134$ \\
\hline -Mood \& substance abuse disorders & 135 \\
\hline -Psychiatric disorders & 136 \\
\hline Dysfunction of appetite and satiety centers in brain & 137 \\
\hline Dysfunction of frontal cortex of brain that controls impulsive eating & 138,139 \\
\hline Problem with brain neuro-transmitters & $|40| 4 \mid$, \\
\hline ADHD in children leading to adult obesity & 142 \\
\hline $\begin{array}{l}\text { General Prescription medications-side effects of commonly prescribed drugs } \\
\text { (drugs for diabetes, hypertension, allergy contraception, corticosteroids \& health issues) }\end{array}$ & 143 \\
\hline $\begin{array}{l}\text { Psychiatric Prescription Drugs -side effects } \\
\text { (Prescription drugs-for mental health issues-schizophrenia, depression, anxiety, mood etc), }\end{array}$ & 128,144 \\
\hline Pregnancy & $67,143-146$ \\
\hline Mothers age affecting childhood obesity & 105,147 \\
\hline Ageing & 148,149 \\
\hline $\begin{array}{l}\text { Pattern of body fat distribution } \\
\text { (-visceral vs. subcutaneous fat distribution) }\end{array}$ & $26,41,150,151$ \\
\hline Genetics & $152-154$ \\
\hline Low BMR & 155 \\
\hline Stress (general stress ) Postpartum stress & $156-159$ \\
\hline Job strain & 158,159 \\
\hline
\end{tabular}

Table I I Possible socio-cultural \& psychological factors implicated in obesity and overweight published in literature

\begin{tabular}{ll}
\hline Socio-cultural \& psychological causes of obesity & References \\
\hline Food marketing and advertising & $160-162$ \\
Hidden calories & $21,163-167$ \\
Culture & $168-170$ \\
Family \& Parental influences & 171,172 \\
Migration \& acculturation & $162,174-180$ \\
\hline Psychological factors & \\
\hline Mood & 181 \\
Depression & 182 \\
Self esteem & 183 \\
Emotional problem & $53,184-186$ \\
\hline
\end{tabular}

The proven causes of overweight and obesity documented in

Literature: Basically excess weight results from energy imbalance caused when there is surplus energy intake (i.e. eating more calories than is actually needed), or decreased energy expenditure (not burning enough of consumed calories through regular physical activity, exercise \& metabolism) or a combination of surplus energy intake and decreased energy expenditure. This situation where energy intake is more than energy output leads to positive energy balance and energy storage, which manifests as fat accumulation, weight gain, overweight and obesity. A person becomes fat when there is excess fat intake. The excess fat fills up adipose tissue which swells up. If available adipose tissues are not sufficient for the excess fat, body makes more fat cells and adipose tissues to store the excess fat. This excess fat manifests as 'obesity bulges' or 'fat swells'. Sometimes obesity can still result from unknown reasons despite increase in activity and diet control. Genetic pre-disposition to overweight, inherited traits from family tree, and presence of so called 'thrifty genes' that help to conserve calories, despite absence of famine, have been offered as reasons for obesity.

Several factors ${ }^{46}$ published in literature contribute to or cause the obesity epidemic, and as more research in weight management continues, more contributing factors continue to be found. These 
factors are grouped into many related categories such as (i)diet, (ii) inactivity, (iii) lifestyle and eating behaviour, (iv) health conditions \& medications, (v) environmental factors (vi) food processing and preparation methods, (vii) genetics (viii) body fat distribution (ix) food marketing and advertising, (x) mothers age(xi) pregnancy, (xii) culture (xiii) family factors, as well as (xiv)psycho-social factors and related conditions. These groups of related factors will be discussed in detail, and tabulated in Table 6-11.

I. Diet related factors that cause obesity: This group of factors is among the most important ones attributed to causing the obesity and overweight epidemic especially in developed countries where there is abundant supply of tasty, heavily advertised and inexpensive edible foods. Foods are inexpensive because of agricultural policies and techniques in some developed countries. In the USA for example, farmers get subsidies for corn, soy, wheat and rice through the Farm Bill which makes products from these subsided crops less expensive compared to fresh fruits and vegetables that get no such subsidies. Many experts are of the opinion that if people can control their dietary intake, it will go a long way in curtailing the obesity problems.

Dietary factors contributing to obesity include the food portion size, fat intake, high intake of other caloric macronutrients as well as intake of fried food, fast and junk foods. Dietary factors also include consumption of soft drinks and caloric beverages, as well as low intake of fiber, fruits and vegetables. It may also include, over-eating or binge eating, use of artificial sweeteners and high fructose corn syrup as well as insufficient dietary calcium intake. Not breastfeeding of child, shortened duration of breastfeeding or increased formula feeding of child can result in childhood obesity. Intestinal microbes are some of the other dietary factors implicated in obesity epidemic. The list of possible diet related factors are presented in Table 6. Some of these factors and supporting research are described below:

a. Food portion size: Food, in developed countries, is easily available all year round and quite inexpensive, frequently advertised in television and billboards, very tasty and served in large portions, or served with large plates. Large food portions are served as "all you can eat buffets" or "super-sized meals", "king size" or "queen size" meals and free drink refills in homes and some restaurants. People therefore tend to consume large amounts of food more frequently, and very few people experience the hunger observed in some developing countries.

On the other hand, affluent people in developing countries also tend to over eat and also do less activity because they have disposable incomes to purchase excess amount of food both home grown or imported foods. They can also afford to buy labor or outsource house work and childcare. Affluent people also do less walking and rather move around in cars, thereby minimizing opportunity to burn food calories.

Increased food portion size and frequent consumption of energy dense foods increase caloric intake. If there is no corresponding physical activity to burn off some consumed excess calories or if metabolism is slow, this lack of energy expenditure leads to excess weight and hence obesity and overweight. Large food portion size and frequent consumption of readily available food have been reported to contribute to the upward trends in obesity and overweight problems. ${ }^{47-49}$

b. High fat intake: High intake of total fat, saturated fat and trans fat have also been implicated in the obesity and overweight problems. ${ }^{50,51}$

c. Fast foods \& Fried foods: Many people live a busy lifestyle and in most dual income families, both parents work outside the home and there is little time to prepare and cook elaborate meals from the scratch except on weekends. Hence many consumers, including children, resort to fast food restaurants where the food is fast, convenient, affordable and tastes good but the food is sometimes fried, high in salt, sugar and fat. This excessive intake of fast foods and fried foods has contributed to the obesity problem. ${ }^{52-55}$

d. Junk foods: Junk foods are packaged convenience foods or snacks with low nutritional value. Since such foods contain very little nutrients, frequent consumption of junk foods leads to un-healthy weight gain and obesity especially in children. ${ }^{56}$

e. Soft drinks, high caloric beverages \& alcoholic drinks: Consumers especially children ${ }^{55-57}$ who drink these caloric beverages such as soft drinks, juices, juice blends, energy drinks and alcohols tend to consume them in large quantities and at a fast rate because of their sweetness or alcoholic content. Since these drinks have low satiety values, consumers eat solid foods, in addition to the drinks, which results high in caloric intake. Consumption of soft drinks ${ }^{58}$ or, high caloric drinks, sugar flavored tea, creamy coffee, sugar sweetened beverages, energy drinks, juices and blends, have been reported to play a role in obesity. ${ }^{59-61}$ Similarly excessive consumption of alcoholic drinks has been implicated as possible causes of obesity. ${ }^{62}$

f. Over eating and binge eating including snack foods: Consumers who over eat specialty foods high in free sugar and fat, tend to store more calories that lead to overweight. ${ }^{54-64}$ Children and adolescents who consume a lot of snack foods (chips, baked goods, cookies, candies, beverages) in addition to traditional family foods are at high risk of childhood obesity. ${ }^{55,59}$

g. Consumption of High Fructose Corn Syrup (HFCS) \& Artificial Sweeteners: Consumption of HFCS in sweetened foods and beverages has been implicated in the obesity epidemic. ${ }^{70,75}$ Similarly artificial sweeteners have been implicated indirectly to increase obesity by increasing food cravings. ${ }^{60,61}$

h. Insufficient dietary calcium: Consumption of insufficient dietary calcium has been implicated as one of the causes of obesity. ${ }^{62}$

i. Low intake of fiber, fruits and vegetables: Fiber in fruits and vegetables gives bulk to the diet, are very filling and reduce the amount of caloric macronutrients consumed and absorbed from food. However, a diet low in fiber, fruits and vegetables can lead to high intake of caloric macronutrients. Reduced intake of fiber can lead to high intake of non fiber foods and increase amount of absorbed calories. Studies have implicated lack of intake of fiber, fruits and vegetables to the increasing obesity trends. $^{63,64}$

j. Not breast feeding a child or shortened breast feeding duration : Several studies have shown that babies who were not breastfed at all but rather fed on infant formula, or babies who had very short duration of breastfeeding, had a higher 
rates of obesity and overweight compared to babies breast fed for long duration. ${ }^{69}$ Prolonged and exclusive breastfeeding on the other hand have been suggested to be protective factors in obesity in children. ${ }^{70-72}$ There is also high risk of obesity in both mothers and babies if mothers did not breast feed. ${ }^{73}$

k. Intestinal microbes: The human gut is a habitat for different types and amounts of bacteria and other microbes that interact with each other and their human host, and consequently affect nutrition and metabolism of foods. ${ }^{74}$ These gut microbes play useful roles in metabolism such as synthesis of B-group vitamins and vitamin $\mathrm{K}$, absorption of ions (such as $\mathrm{Mg}+2$, $\mathrm{Fe}+2, \mathrm{Ca}+2$ ), synthesis of short chain fatty acids (such as butyrates, propionates, acetates), that act as energy source for colon and liver cells. These microbes also facilitate stimulation of cell growth, repression of growth of bad bacteria and activation of immune system to respond to invading harmful microbes. The intestinal microbes also facilitate removal of some end products of fermentation such as hydrogen and play a role in protection from some diseases. ${ }^{75}$ Changes in the types and amounts of these microbes occur due to the type of foods consumed or medications used. Changes in quantity and types of these gut microbes and their interaction with intestinal cells have been linked to obesity in some individuals. ${ }^{76-80}$

1. Use of antibiotics in food animals and other human foods: Antibiotics are used in food animals to enhance animal growth, increase their productivity, and also prevent infection in overcrowded pens and farms. Antibiotics are commonly used in farms for raising pigs, cattle, chicken, fish, etc. The downside to use of antibiotics is that antibiotic overuse or abuse has been implicated not only in the rise of superbugs ${ }^{81,82}$ but also, in inducing overweight and obesity in humans. ${ }^{83,84}$

II. Activity related factors that cause obesity: The most important factors, besides dietary factors, implicated in causing the obesity problem are activity related factors such as physical inactivity, lack of exercise or too little exercise, sedentary lifestyle, increased reliance on personal or public automobiles and other easy means of transportation, sedentary activities, reliance on mechanized manufacturing, increased screen time as well as increased sitting time. Table 7 shows a list of some activity related factors that cause obesity and overweight. Some of these factors and supporting research are described below.

a. Physical inactivity: The level of physical activity and exercise has decreased in many populations because of convenient transportation and technology that have reduced amount of time and energy spent in work or play. Many manufacturing or construction jobs that cause sweat and use physical labor are now automated. Most people drive instead of walking, even for short distances; others prefer to take elevators or lifts instead of walking the stairs. Children are driven to school by cars and buses instead of walking to school, for various reasons such as safety, convenience especially during inclement weather, distance from school, fear of child molesters, fear of abductors and kidnapers. House work has been made easy with machines and electronic household gadgets and people hardly sweat any more. Some affluent people even outsource house work, child care and yard work. Opportunity to burn excess calories is therefore scarce, so most unused food energy is stored as fat, contributing to the obesity epidemic as discussed in some studies. ${ }^{85-87}$ b. Lack of exercise. Lack of exercise (or programmed physical activity such as sports, going to gym or taking walks) has been implicated in the obesity epidemic in adults and children. Because of lean budgets, many schools are cutting off money allocated to physical exercise (popularly known as PE) and re-allocating the fund to other school needs. If children do not form the habit of exercising early in life, they might become inactive and gain weight and become obese; obese kids end up becoming obese adults with its adverse consequences. ${ }^{88-91}$

c. Sedentary activities \& too much sitting time: Sedentary activities and too much sitting time lead to decreased energy expenditure and increased energy storage that results in fat storage, low lean body mass, overweight and obesity. People whose daily jobs involve prolonged sitting in one place such as bus, train, truck and taxi drivers, or sedentary office workers have been known to gain weight excessively if they make no attempts at being physically active each day according many studies. ${ }^{92,93}$ Similarly sitting down too much, (including immobility / being wheel chair bound) whether at home or at work, leads to excess weight gain. ${ }^{94}$

d. Prolonged screen time: Children and adults who sit in one place watching television, playing video games or computer games or spending a lot of time on the internet, tend to gain weight if they make no attempt to include exercise and physical activity in their routines. This can lead to obesity according to many studies. ${ }^{95,96}$

III. Lifestyle and behaviour related factors that cause obesity: Several lifestyle and behaviour factors have been implicated as the causes of obesity. These are documented in several studies listed in Table 8 and include the following:

a. Sedentary life style $\mathrm{e}^{97-99}$

b. Eating out frequently in traditional and non- traditional restaurants instead of cooking at home $\mathrm{e}^{100,101}$

c. Frequent vacations involving sumptuous dining and wining ${ }^{102}$

d. Insufficient sleep or lack of sleep ${ }^{103}$

e. Staying home watching television and movies all day ${ }^{104,105}$

f. Shift work, night shift and unusual work schedules ${ }^{106}$

g. Eating patterns and eating behaviours ${ }^{107,108}$

h. Too much sitting instead of moving ${ }^{109}$

i. Sudden discontinuation of smoking. ${ }^{110,111}$

IV. Environmental related factors that cause obesity: Several environmental factors (Table 9) have been implicated as contributing to the obesity epidemic as documented in several studies. These include:

a. Food environment ${ }^{112-114}$

b. Unsafe recreation \& living areas ${ }^{115-118}$

c. Unwholesome foods ${ }^{119}$

d. Low ambient temperature: Sometimes obesity could result from sitting for long time in low ambient temperatures. Several reports have implicated sedentary lifestyle in air conditioned environment in the cause of obesity. ${ }^{120-122}$ 
e. Food deserts: Other environmental conditions leading to obesity include food deserts. Food deserts are geographic areas or communities with limited or no access to fresh, affordable, culturally relevant nutritious foods. It is also a place without nearby grocery stores, supermarkets, and neighbourhood farms and farmers markets. In food deserts, healthy foods (e.g. fresh fruits and vegetables, fresh low fat dairy, whole grains, lean protein \& other whole foods) are difficult to obtain because of logistical, transportation, availability of such foods or economic barriers. Instead of healthful grocery stores, food deserts harbor convenience stores, corner stores and fast food joints that sell processed foods high in fat, sugar and salt all day. Studies have implicated food deserts in the rising obesity epidemic in poor communities. ${ }^{123,124}$

f. Obesogenic Chemicals \& Foods in the Environment. Certain culprit chemicals in the food environment, the so called obesogenic chemicals, have been implicated to disrupt metabolism and induce weight gain, thereby causing obesity. ${ }^{125,126}$ These chemicals include:

i) Endocrine disrupters: The endocrine disruptors,(Bisphenol A, phthalates, atrazine, organotins and perfluorooctanoic acid present in non stick pans and many other chemicals) have been implicated in causing obesity $^{127,128}$

ii) Obesogenic foods: Similarly consuming obesogenic foods coupled with obesogenic activity have been implicated in the obesity epidemic. ${ }^{129}$

V. Health conditions, body dysfunctions \& medications related causes of obesity: Many health conditions are implicated in causing obesity according to reports in literature. These include: hormonal malfunctions, mental health and psychological problems, appetite and satiety dysfunction in the brain, problems with brain neurotransmitters, problems with general prescription medications, side effects of psychiatric drugs, as well as attention deficit hyperactive disorder (ADHD). These conditions which result in obesity are listed in Table 10 and have been described in the studies listed below.

\section{a. Hormonal malfunctions and syndromes}

i. Hypothyroidism ${ }^{130}$

ii. Prader Willie syndrome ${ }^{131}$

iii.Polycystic ovarian syndrome or PCOS ${ }^{132-134}$

iv. Cushing's syndrome ${ }^{135}$

v. Other endocrine diseases, ${ }^{136}$ such as growth hormone deficiency

vi. Other eating disorders such as binge eating disorder and night eating syndromes 16 .

b. Mental health and psychiatric problems: Similarly mental health problems/ psychiatric disorders have been implicated in causing obesity. These include: Dépression, ${ }^{137-139}$ Schizophrenia, -mood and anxiety disorders have been implicated in obesity and overweight according to published studies. ${ }^{139-141}$

c. Appetite and satiety center dysfunction in brain: The brain also plays a role in obesity problem. Dysfunction of the satiety and appetite centers in hypothalamus of the brain $^{142}$ have been implicated in causing obesity

d. Frontal cortex dysfunction in the brain: Dysfunction in the frontal cortex which controls impulse, lead to extreme eating behaviours that result in overweight and obesity ${ }^{143,144}$

e. Problem with brain neurotransmitters: Sometimes obesity could be caused by the problems with brain neuro -transmitters that lead to binge eating ${ }^{145}$

f. Attention Deficit Hyperactive Disorder (ADHD): Some mental health disorders like ADHD in children has been implicated in causing adult obesity. ${ }^{146}$

g. Prescription drugs for general diseases: Prescription drugs for various diseases have been implicated in the obesity problem as weight gain is one of the side effects of these drugs. Common prescription drugs for general diseases like diabetes, hypertension or conditions like allergy, contraception, corticosteroids and other health issues have been implicated in causing obesity. ${ }^{147}$

h. Psychiatric medications: Some psychotropic drugs prescribed for mental health disorders also have weight gain as their side effects. ${ }^{138-140}$

i. Pregnancy: Many women gain weight following their first and subsequent pregnancies. ${ }^{69,148}$ If efforts are not made to lose the pregnancy-induced weight gain or the so called 'puppy fat', the weight persists and gets larger with the next and subsequent pregnancies. Frequent pregnancies as well as short inter-pregnancy interval (IPI) are correlated with high weight gain and obesity in women. ${ }^{148-151}$

j. Age of mother: Mother's age has been reported to affect not only child hood obesity but also visceral fat distribution and accumulation in the mother. ${ }^{106,152}$

k. Ageing and related factors: Both adults and children are capable of developing the obese weight status. However, ageing in some people is accompanied by low muscle mass, lower metabolism, decreased activity level, lower energy expenditure and lower caloric needs. Older people therefore tend to store calories from food much easily and gain weight since their activity level and energy expenditures are slowed down. These decreased energy expenditure and activity levels in older adults have been reported in many studies. ${ }^{153,154}$

I. Factors related to pattern of body fat distribution: An individual's pattern of fat distribution such as visceral versus subcutaneous fat also plays a role in the causes of obesity. ${ }^{27,42,156,157}$

m. Genetic factors that cause of obesity: Some people are born big in their families and always have high BMI whether they diet or not, while others do not gain weight no matter how much food they consume. Genetics is an important factor affecting obesity and overweight as BMI status runs in some families and is a heritable trait. ${ }^{102,158-160}$ Genetics plays a greater role in body fat distribution than environmental factors.

n. Lower basal metabolic rate (BMR) as a cause of obesity: The BMR is the energy in calories that the body spends to function at rest and for supporting vital body functions in 
neutral temperate environment and post absorptive state. Some studies suggest that obese people have lower BMR compared to non-obese counterparts. However it is difficult to predict BMR in obese patients according to some reports. ${ }^{161}$

o. General and postpartum stress as causes of obesity: Physical and mental stress have been implicated as potential causes of obesity. ${ }^{162,163}$ Job strain and job related stress have also been implicated in the causes of obesity and overweight. ${ }^{164,165}$ Postpartum stress is also implicated as causes of maternal weight retention and obesity. ${ }^{166}$

VI. Socio-cultural \& psychological factors that cause obesity \& overweight: Many factors including food marketing and advertising, hidden calories, culture, family factors, parental influences, migration and acculturation as well as other psychosocial factors cause obesity. These are listed in Table 11.

a. Food marketing and advertising: Media marketing and advertising of foods and snacks such as sweetened beverages, soft drinks, salty \& sugary snacks, baked foods and sweetened cereals entice children and young adults into eating these foods very often. The more advertising the children and adolescents are exposed to advertised foods, the more they patronize these foods. Consumption of these advertised foods lead to weight gain and eventual overweight and obesity. ${ }^{167-169}$

b. Hidden calories: Few reports have implicated hidden calories as some of the causes of rising obesity and overweight trends. ${ }^{21,169,170}$ Many factors including social, political, economic and lifestyle factors that resulted in the increasing weight trends around the world are indirect and hidden from the consumer according to some published reports. ${ }^{21,171}$

c. Culture: Although obesity and overweight are discouraged by health care personnel because of the health and quality of life consequences, these types of body weight status are sometimes welcomed and revered in some developing countries. In such countries, high body mass is regarded as evidence of good living and a sign of wealth, fertility and beauty. ${ }^{172,155}$ The reason for high regard for obese and overweight people in low and middle income countries is because an overweight /obese person is presumed to be wealthy or at least richer than the average citizen. An overweight person is perceived to be pretty well off since he or she can afford excess food in a place where food is sometimes scarce, seasonal, not easily available and not affordable by most people. There is an erroneous perception that only the rich people can afford to eat excess food or gain excessive weight.

Moreover many indigenous dresses like wrappers and flowing gowns fit better on a person with ample body mass, or people regarded as 'pleasantly plump' compared to a 'skinny' or 'lean' persons. In addition, overweight or obese women are erroneously presumed to be more fertile than their thin counterparts. Many people in developing countries therefore make efforts to eat more food to gain weight so as to be 'respected' in their local communities. In many areas of the world, food has social, cultural and religious uses. In addition, food is sometimes used to express love, power, reward, prestige, control and sometimes hostility in some cultures.
Recent studies however report that as socio economic status in poor countries increase, obesity trend increases just like in developed countries; weight gain which was no problem in the past is now a worry for developing countries because of obesity co-morbidities such as diabetes, hypertension, heart disease that accompany obesity. ${ }^{173}$. In some developed countries, some people use food as a reward, and some people deliberately over eat and this consequently results in obesity. ${ }^{174}$

a. Family and parental influences: The type of food choices and dietary patterns of families affect the weight of adults and children in the households. Children exposed to high food consumption or to consumption of high caloric food and sugary drinks, tend to grow up with such eating patterns and food preferences that were formed early in life. Similarly, families consuming few fruits and vegetables or none at all, tend to pass these eating habits to their children. ${ }^{175}$

b. Family activities and habits: Engagement in sedentary activities by adults in the family or non-participation in physical activities, tend to influence children who view adults as role models. Reports from literature show that having obese or overweight parents and family members or friends , tend to influence children and is associated with obesity in children. ${ }^{175,176}$

c. Migration and acculturation: Because of insecurity and economic upheavals in many parts of the world, many people are migrating from their native countries to richer countries in search of better life and opportunities in education, medicine, jobs, technology and finance and above all, for safety. Many studies have documented the association between migration and obesity in people who migrate from low or mid income countries to high income countries. ${ }^{162,176,177}$ As people move from their traditional environments to rich host countries, their lifestyle, eating habits and physical activity habits change. Consequently, migration, acculturation and changes in feeding and activity behaviours have resulted in obesity in immigrants. ${ }^{163,178,179}$ Studies have also shown that immigrants who try to retain their cultural feeding and activity practices despite the prevailing norms in their rich host countries tend to reduce the prevalence of obesity in their new communities. ${ }^{168,180,181}$

d. Psychological factors: Some studies have shown that people who are depressed tend to eat comfort food to elevate their mood, thereby leading to obesity. ${ }^{182}$ Depression can occur in adults, children and adolescents. Depression has a bidirectional relationship with obesity, hence depression can be a cause of obesity as well as a consequence of obesity. ${ }^{53,183}$ Some people who have low self esteem and poor body image tend to over eat and become obese. ${ }^{184}$ Some obese children also tend to have emotional problems as reported in some studies. ${ }^{1}$ Body dissatisfaction in some adolescents can lead to depression and over consumption of foods which can lead to overweight and obesity. Body dissatisfaction in obese adolescents has been reported to be more common in girls than boys. ${ }^{185,186}$

\section{Strategies for prevention of obesity and overweight:}

Several strategies for preventing overweight and obesity involve raising awareness about obesity and its consequences, food calories and their effects as well as diet control. It also involves reading food labels, making good food choices and eating healthy foods. On a personal level, a consumer who has a hunch that certain foods or 
activities could likely cause their weight gain should stop such foods or activities and err on the side of caution until proven otherwise. Sometimes peoples gut feelings about a food or a habit tend to be right, though this is not always the case. Government regulators should mandate the sites for healthy food and grocery stores in various neighbourhoods instead of creating food deserts. They should also mandate food manufacturers to make and market healthy food products.

Other important strategies include physical activity and behaviour modification. Local, state and federal government regulators should encourage physical activity at personal and community levels by building better walk ways, sidewalks, bicycle paths, recreation areas and healthy living environments. Policies that encourage physical activity should be created by all levels of government. The Mass in Motion program, a public health program in the state of Massachusetts (MA) in the USA, is a model example of encouraging physical activity and good nutrition starting at local and community levels. The state of MA is one of the healthiest states in the USA ${ }^{187,188}$ (Massachusetts

Table 12 Strategies for prevention of obesity and overweight has a high number of people who have health insurance, excellent healthcare for mothers and children, good health promotion and adequate healthcare for all in the general population), Such good public health programs and general healthcare in MA which promote population health and healthy activity are worthy of emulation by other states and countries. For optimal health, people should follow the regulatory guidelines for good nutrition, food and health such as the USDA My Plate Food Guide of 2015, ${ }^{189}$ the 2015-2020 Dietary Guidelines for Americans or DGA 190 as well as the Healthy People 2020 Guideline or HP 2020191.

A joint effort by individuals and families, neighbourhoods, communities \& villages, towns \& cities, schools, colleges \& universities, states and countries are important in fighting this epidemic. In addition, businesses, for profit and non-profit organizations, as well as various levels of government in various countries should partner together to prevent or reduce obesity and its consequences so as to improve population health. Some strategies for prevention of obesity are summarized in Table 12.

Strategies for Prevention of Obesity and Overweight:

Consumer education on consequences of excess calories

Consumer awareness of hidden and obvious calories as causes of overweight and obesity

Reading food labels \& properly interpreting calorie claims and making healthy food choices

Cutting down calories by consuming low calorie foods, low calorie beverages and reducing sweet /fatty snacks; cutting down on sweet or creamy drinks and beverages or eliminating them at some eating occasions

Adopting diets known to lower blood sugar, blood pressure \& heart disease e.g. diabetic diet, vegetarian diet, Mediterranean diet \& DASH Diet and TLC diet for high cholesterol

Increasing physical activity, doing some activity every day and avoiding sedentary lifestyle, increase walk time, standing time, and exercise time; creating environments suitable for physical activity.

Food Portion size control/total calorie intake reduction/Use of small plate size

Use My Plate food guide for selecting food to eat and follow a healthy eating pattern

Follow the recent 2015 DGA which emphasizes healthy food pattern and reducing added sugar, excess fat and added salt as well as following the HP 2020 guidelines

Use low calorie substitutes in place of high calorie foods

Gradual sugar and fat reduction as well as gradual reduction of salty caloric foods

Eating more fresh foods-fruits, vegetables, whole grains and foods high in fiber instead of processed foods high in fat, sugar, salt and additives.

Behavior and lifestyle modification

Improve sleep, reduce stress, reduce alcohol and smoking

Eating in moderation high caloric foods even if they high in other nutrients or even if they are the only options available e.g. avocado, nuts, olive oil, cheese foods, full fat milk(whole milk)

Eating in moderation any food promoted as healthy, natural or traditional as they may also be high in calories

Research food before eating whether at home or in restaurants

Counting calories in all foods and snacks eaten at home or outside the home

Make healthier food choices by observing the calorie count laws and the nutrition facts panel and by being cognizant of calorie consumption in each meal at restaurants or home.

Limit unhealthy foods--refined grains, white potato, yam, other white starchy foods, red meat, processed meat

Limit unhealthy beverages, sugary drinks, colas, sweet carbonated beverages, creamy enriched coffees and energy drinks; reduce quantity of fruit juice and alcohol consumed

Limit television time, sitting time, use of computer and video games, screen time

Government to enact laws and policies for good physical activity, good food and health. 


\section{Conclusion}

The obesity epidemic is a reality in many developed and developing countries. A concerted effort is needed to fight the problem. Health care workers and individuals need to know how to assess obesity in private, clinical or community settings. They should also be conversant with the various causes of obesity as well as cost effective prevention and intervention strategies. Public health education on excessive weight gain and its consequences are necessary so as to inform and empower the public. An informed public will be enabled to take appropriate action in making better food choices, increase physical activity, modify their lifestyle and behaviour and do a regular health check so as to fight obesity and promote health.

A healthy public will save healthcare dollars, save lives, safeguard health, minimize use of health care resources which can then be made available for the those most in need of these resources. A healthy public will also lead to increased work productivity and improved quality of life. A concerted effort by individuals, health professionals, educators, businesses and government regulators is needed to fight the epidemic, and will ensure good health and wellness in many populations.

\section{Acknowledgements}

Special thanks go to Dr Lisa Brown, Associate Professor of Nutrition, Simmons College, Boston Massachusetts, USA, for helpful discussions and advice on the manuscript.

\section{Conflict of interest}

The author declares no conflict of interest.

\section{References}

1. Flegal KM, Carroll MD, Kit BK, et al. Prevalence of Obesity and Trends in the Distribution of Body Mass Index Among US Adults, 1999-2010. JAMA. 2012;307(5):491-497.

2. Health USA: Health United States. Obesity \& Overweight Prevalence. CDC Fast Stats; Table 53, Center for Disease Control and Prevention. Atlanta GA, USA; 2014

3. OECD. Obesity Update 2014. Organization for Economic Co operation and Development. 2014.

4. Caballero B. The global epidemic of obesity: an overview. Epidemiol Rev. 2007;29:1-5.

5. Rennie KL, Jebb SA. Prevalence of obesity in Great Britain. Obes Rev. 2005;6(1):11-22.

6. Johnsson T, Olsson S, Ahren B, et al. Agrarian diet and diseases of affluence: do evolutionary novel dietary lectins cause leptin resistance? BMC Endocr Disord. 2005;5:10.

7. Caballero B. A Nutrition Paradox: Underweight and Obesity in Developing Countries. New Engl J Med. 2005;352(15):1514-1516.

8. Kumanyika S, Jeffery RW, Morabia A, et al. Obesity Prevention: The Case for Action. International Journal of Obesity. 2002;26:425-436.

9. WHO. World Health Organization. Controlling the Global Obesity Epidemic: The Challenge. WHO Expert Consultation on Waist Circumference and waist- to-hip ratio, Geneva, Switzerland; 2008.

10. Ogden CL, Carroll MD, Fryar CD, et al. Prevalence of Obesity among Adults and Youth: United States, 2011-2014. NCHS Data Brief. 2015;219:1-8

11. Ogden CL, Carroll MD, Kit BK, et al. Prevalence of childhood and adult obesity in the United States, 2011-2012. JAMA. 2014;311(8):806-814.
12. US Surgeon General. The Surgeon General's Vision for a Healthy and Fit Nation. Office of the Surgeon General (US), 2010.

13. Deitel M. The Surgeon-General's call to action to prevent an increase in overweight and obesity. Obes Surg. 2002;12(1):3-4.

14. Nestle M, Jacobson MF. Halting the obesity epidemic: a public health policy approach. Public Health Rep. 2000;115(1):12-24.

15. Beaglehole, Horton R. Chronic diseases: global action must match global evidence. Lancet. 2010;376(9753):1619-1621.

16. James WP. The epidemiology of obesity: the size of the problem. J Intern Med. 2008;263(4):336-352.

17. Reese MATB. Underweight: A Heavy Concern. Today's Dietitian. 2008;10(1):56.

18. Lazzeri G, Rossi S, Pammolli A, et al. Underweight and overweight among children and adolescents in Tuscany (Italy). Prevalence and short-term trends. J Prev Med Hyg. 2008;49(1):13-21.

19. Uzogara SG. Underweight, the Less Discussed Type of Unhealthy Weight and Its Implications: A Review. American Journal of Food Science and Nutrition Research. 2016;3(5):126-142.

20. WHO. Nutrition Landscape Information Systems, NLIS, Country Profile Indicators Interpretation Guide. Malnutrition In Children and Adults-Underweight, Stunting, Wasting, Overweight, WHO Geneva, Switzerland; 2010.

21. Black RE, Victora CG, Walker SP, et al. Maternal and child under nutrition and overweight in low-income and middle-income countries. Lancet. 2013;382(9890):427-451.

22. Uzogara SG. Obvious and hidden calories in food and their impact on weight, obesity and wellness: A review. Adv Obes Weight Manag Control. 2016;4(5):1-11.

23. Averkamp S. Over fat definition. Fitness for weight loss. 2015.

24. Muth ND. What are the guidelines for the percentage of body fat loss? 2009.

25. General body fat percentage categories for men and women. American Council on Exercise: Table 6.14.

26. Jensen MD, Ryan DH, Apovian CM, et al. The 2013 AHA/ACC/TOS guidelines for the management of overweight and obesity in adults:a Report of the American College of Cardiology/American Heart Association Task Force on Practice Guidelines \& The Obesity Society. $J$ Am Coll Cardiol. 2014;63(25 Pt B):2985-3023.

27. Anuurad E, Shiwaku K, Nogi A, et al. The new BMI criteria for Asians by the regional office for the Western Pacific Region of WHO are suitable for screening of overweight to prevent metabolic syndrome in elder Japanese workers. J Occup Health. 2003;45(6):335-343.

28. Hsu WC, Araneta MR, Kanaya AM, et al. BMI cut points to identify at-risk Asian Americans for type 2 diabetes screening. Diabetes Care. 2015;38(1):150-158

29. Joslin Diabetes Center. What is BMI: BMI for Asian and Asian American adults. Asian American Diabetes Initiative. 2016.

30. Montague CT, O'Rahilly S. The perils of portliness: causes and consequences of visceral adiposity. Diabetes. 2000;49(6):883-888.

31. Hu FB. Obesity Epidemiology. USA: Measurement Techniques, Oxford University Press; 2008.

32. Ashwell M, Mayhew L, Richardson J, et al. Waist-to-Height Ratio is More Predictive of Years of Life Lost than Body Mass Index. PLoS ONE. 2014;9(9):e103483.

33. Ashwell M, Gunn P, Gibson S. Waist-to-height ratio is a better screening tool than waist circumference and BMI for adult cardiometabolic risk factors: systematic review and meta-analysis. Obes Rev. 2012;13:275286. 
34. Ashwell M. Plea for simplicity: Use of waist-to-height ratio as a primary screening tool to assess cardio-metabolic risk. Clinical Obesity. 2012;2(1-2):3-5.

35. Jackson AS, Pollock ML. Steps toward the development of generalized equations for predicting body composition of adults. Can $J$ Appl Sport Sci. 1982;7(3):189-196.

36. Pollock ML, Jackson AS. Research progress in validation of clinical methods of assessing body composition. Med Sci Sports Exerc. 1984;16(6):606-615.

37. Reilly JJ, Wilson J, Durnin JV. Determination of body composition from skinfold thickness: a validation study. Arch Dis Child. 1995;73(4):305310 .

38. Perry M. Ideal body fat percentage chart: How lean can you be? Body composition, Recommended maximum percentage of body fat. 2010.

39. Casey AF. Measuring Body Composition in Individuals with Intellectual Disability: a Scoping Review. J Obes. 2013;2013:628428.

40. American Council on Exercise. What are the guidelines on percentage of body fat loss? Fitness \& healthy living. 2015.

41. CDC Growth Charts for the United States: Methods and Development. USA: Centers for Disease Control and Prevention; 2000.

42. Ogden CL, Flegal KM. Changes in terminology for childhood overweight and obesity. Natl Health Stat Rep. 2010;25:1-5.

43. WHO. WHO Child Growth Standards: Length/Height-for-Age, Weightfor-Age, Weight-for-Length, Weight-for-Height and Body Mass Indexfor-Age: Methods and Development. Switzerland: Publications of World Health Organization; 2006.

44. Mei Z, Ogden CL, Flegal KM, et al. Comparison of the prevalence of shortness, underweight, and overweight among US children aged 0 to 59 months by using the CDC 2000 and the WHO 2006 growth charts. $J$ Pediatr. 2008;153(5):622-628.

45. Chaput JP, Perusse L, Despres JP, et al. Findings from the Quebec Family Study on the Etiology of Obesity: Genetics and Environmental Highlights. Curr Obes Rep. 2014;3:54-66.

46. NHLBI. What causes obesity? Health conditions that cause obesity. USA: National Heart, Lung \& Blood Institute, National Institute of Health; 2015.

47. Livingstone MB, Pourshahidi LK. Portion size and obesity. Adv Nutr. 2014;5(6):829-834.

48. Rolls BJ, Roe LS, Meengs JS. Larger portion sizes leads to sustained increase in energy intake over two days. $J$ Am Diet Assoc. 2006;106(4):543-549.

49. Nielsen SJ, Popkin BM. Patterns and trends in food portion sizes, 1977 1998. JAMA. 2003;289(4):450-453.

50. Lee CY. The Effect of High-Fat Diet-Induced Patho-physiological Changes in the Gut on Obesity: What Should be the Ideal Treatment? Clin Transl Gastroenterol. 2013;4:e39.

51. Phillips CM, Kesse-Guyot E, McManus R, Hercberg S, Lairon D, et al. High dietary saturated fat intake accentuates obesity risk associated with the fat mass and obesity-associated gene in adults. J Nutr. 2012;142(5):824-831.

52. Currie J, Della Vigna S, Moretti E, et al. The effect of Fast Food Restaurants on Obesity and Weight Gain. American Economic Journal: Economic Policy, American Economic Association. 2010;2(3):32-63.

53. Bowman SA, GortmakerSL, Ebbeling CB, et al. Effects of fast food consumption on energy intake and diet quality among children in a national household survey. Pediatrics. 2004;113(1 Pt 1):112-118.
54. Ebbelling CB, Sinclair KB, Pereira MA, et al. Compensation for energy intake from fast food and among overweight and lean adolescents. JAMA. 2004;291(23):2828-2833.

55. Bray GA, Nielsen SJ, Popkin BM. Consumption of high-fructose corn syrup in beverages may play a role in the epidemic of obesity. Am J Clin Nutr. 2004;79(4):537-543.

56. Datar A, Nicosia N. Junk Food in Schools and Childhood Obesity. $J$ Policy Anal Manage. 2012;31(2):312-337.

57. Sahoo K, Sahoo B, Choudhury AK, et al. Childhood obesity: causes and consequences J Family Med Prim Care. 2015;4(2):187-192.

58. James J, Kerr D. Prevention of childhood obesity by reducing soft drinks Inter J of Obesity. 2005;29:S54-S57.

59. Walker RW, Dumke KA, Goran MI. Fructose content in popular beverages made with and without high fructose corn syrup. Nutrition. 2014;30(7-8):928-935.

60. Ogden CL, Kit BK, Carroll MD, et al. Consumption of sugar drinks in the United States, 2005-2008. NCHS Data Brief. 2011;71:1-8.

61. Brown CM, Dulloo AG, Montau JP. Sugary drinks in the pathogenesis of obesity and cardiovascular disease. Int J of Obesity (Lond). 2008;32(supp 6):S28-S34.

62. Sayon-Orea C, Bes-Rastrollo M, Nuñez-Cordoba JM, et al. Type of alcoholic beverage and incidence of overweight/obesity in a Mediterranean cohort:the SUN project. Nutrition. 2011;27(7-8):802808

63. Ludwig DS, Majzoub JA, Al-Zahrani A, et al. High Glycemic Index Foods, Overeating and Obesity. Pediatrics. 1999;103(3):E26.

64. Anderson PM, Butcher KE. Childhood obesity: Trends and potential causes. Future Child. 2006;16(1):19-45.

65. Yang Q. Gain weight by "going diet?" Artificial sweeteners and the neurobiology of sugar cravings. Yale J Biol Med. 2010;83(2):101-108.

66. Mattes RD, Popkin BM. Non-nutritive sweetener consumption in humans: effects on appetite and food intake and their putative mechanisms. Am J Clin Nutr. 2009;89(1):1-14.

67. Tremblay A, Gilbert JA. Human obesity: is insufficient calcium / dairy intake part of the problem? J Am Coll Nutr. 2011;30(5suppl 1):449S-453S

68. Grooms KN, Ommerborn MJ, Pham DQ, et al. Dietary Fiber Intake and Cardio metabolic Risks among US Adults, NHANES 1999-2010. Am J Med. 2013;126(12):1059-1067.

69. Ledoux TA, Hingle MD, Baranowski T. Relationship of fruit and vegetable intake with adiposity: a systematic review. Obes Rev. 2011;12(5):e143-e150.

70. Yan J, Liu L, Zhu Y, et al. The association between breastfeeding and childhood obesity: a meta-analysis. BMC Public Health. 2014;14:1267.

71. Yang Z, Huffman SL. Nutrition in pregnancy and early childhood and associations with obesity in developing countries. Marten Child Nutr. 2013;9(Suppl 1):105-119.

72. Vafa M, Moslehi N, Afshari S, et al. Relationship between Breastfeeding and Obesity in Childhood. J Health Popul Nutr. 2012;30(3):303-310.

73. Arenz S, Ruckerl R, Koletzko B, et al. Breast-feeding and childhood obesity-a systematic review. Int $J$ Obes Relat Metab Disord. 2004;28(10):1247-1256

74. Arenz S, von Kries R. Protective effects of breastfeeding against obesity in childhood. Can a meta-analysis of observational studies help to validate the hypothesis? Adv Exper Med Biol. 2005;569:40-48. 
75. Kramer MS, Matush L, Vanilovich I, et al. Effects of prolonged and exclusive breastfeeding on child height, weight, adiposity and blood pressure at age 6.5y: evidence from a large randomized trial. Am J Clin Nutr. 2007;86(6):1717-1721.

76. Metzger MW, McDade TW. Breastfeeding as obesity prevention in the United States: a sibling difference model. Am J Hum Biol. 2010;22(3):291-296.

77. Jwa SC, Fujiwara T, Kondo N. Latent protective effects of breastfeeding on late childhood overweight and obesity: a nationwide prospective study. Obesity (Silver Spring). 2014;22(6):1527-1537.

78. Stuebe A. The Risks of Not Breastfeeding for Mothers and Infants. Rev Obstet Gynecol. 2009;2(4):222-231.

79. Ramakrishna BS. Role of gut microbiota in nutrition and metabolism. $J$ Gastroenterol Hepatol. 2013;28(suppl 4):9-17.

80. O'Sullivan A, Farver M, Smilowitz JT. The influence of early infant feeding practices on the intestinal microbiome and body composition in infants. Nutr Metab Insights. 2015;8(suppl 1):1-9.

81. Blaut M, Klaus S. Intestinal microbiota and obesity. Handb Exp Pharmacol. 2012;209:251-273.

82. Aron-Wisnewsky J, Doré J, Clement K. The importance of the gut microbiota after bariatric surgery. Nat Rev Gastroenterol Hepatol. 2012;9(10):590-598.

83. Diamante M, Blaak EE, de Vos WM. Do nutrient-gut-microbiota interactions play a role in human obesity, insulin resistance and type 2 diabetes? Obes Rev. 2011;12(4):272-281.

84. Barza M. Potential mechanisms of increased disease in humans from antimicrobial resistance in food animals. Clin Infect Dis. 2002;34(Suppl 3):S123-S125.

85. Landers TF, Cohen B, Wittum TE, et al. A Review of Antibiotic Use in Food Animals: Perspective, Policy, and Potential. Public Health Rep. 2012;127(1):4-22.

86. Van Boeckel TP, Brower C, Gilbert M, et al. Global trends in antimicrobial use in food animals. PNAS. 2015;112(18):5649-5654.

87. Berkeley Wellness. Are antibiotics making us fat? Be Well Updates, UC Berkeley Wellness Newsletter, 2015.

88. Cecchini M, Sassi F, Lauer JA, et al. Tackling of unhealthy diets, physical inactivity and obesity: health effects and cost-effectiveness. Lancet. 2010;376(9754):1775-1784.

89. Lee IM, Djousse L, Sesso HD, et al. Physical activity and weight gain prevention. JAMA. 2010;303(12):1173-1179.

90. Hu FB. Physical Activity, Sedentary Behaviours, and Obesity. Obesity Epidemiology. New York: Oxford University Press; 2008. p. 301-319.

91. Pedersen BK, Febbraio MA. Muscles, exercise and obesity: skeletal muscle as a secretory organ. Nat Rev Endocrinol. 2012;8(8):457-465

92. Barnes AS, Coulter SA. Obesity and Sedentary Lifestyles: Risk for Cardiovascular Disease in Women. Tex Heart Inst J. 2012;39(2):224227 .

93. McTiernan A, Sorensen B, Irwin ML, et al. Exercise effect on weight and body fat in men and women. Obesity (Silver Spring). 2007;15(6):14961512 .

94. Owen N, Healy GN, Matthews C, et al. Too Much Sitting: The Population-Health Science of Sedentary Behavior. Exerc Sport Sci Rev. 2010;38(3):105-113.

95. DeBoer M, Muinos W. Just 1 Hour of Daily TV Boosts Kids' Obesity Risk. USA: Paper presented on April 26, 2015, Pediatric Academic Societies Annual Meeting; 2015.
96. Grontved A, Hu FB. Television viewing and risk of type 2 diabetes, cardiovascular disease, and all-cause mortality: a meta-analysis. JAMA. 2011;305(23):2448-2455.

97. Gany F, Bari S, Gill G, et al. Step On It! Impact of a Workplace New York City Taxi Driver Health Intervention to Increase Necessary Health Care Access. Am J Public Health. 2015;105(4):786-792.

98. Larson N, Neumark-Sztainer D, Laska MN, et al. Young Adults and Eating Away from Home: Associations with Dietary Intake Patterns and Weight Status Differ by Choice of Restaurant. J Am Diet Assoc. 2011;111(11):1696-1703.

99. Cooper JA, Tokar T. A prospective study on vacation weight gain in adults. Physiol Behav. 2016;156:43-47

100. Nielsen LS, Danielsen KV, Sorensen TI. Short sleep duration as a possible cause of obesity: critical analysis of the epidemiological evidence. Obes Rev. 2011;12(2):78-92.

101. Cox R, Skouteris H, Rutherford L, et al. Television viewing, television content, food intake, physical activity and body mass index:a crosssectional study of preschool children aged 2-6years. Health Promot $J$ Austr. 2012;23(1):58-62.

102. Eisenmann JC, Bartee RT, Smith DT, et al. Combined influence of physical activity and television viewing on the risk of overweight in US youth. Int J Obes (Lond). 2008;32(4):613-618.

103. Kim MJ, Son KH, Park HY, et al. Association between shift work and obesity among female nurses: Korean Nurses Survey. BMC Public Health. 2013;13:1204.

104. Sominsky L, Spencer SJ. Eating behaviour and stress: a pathway to obesity. Front Psychol. 2014;5:434.

105. Bouchard C. Defining the genetic architecture of the predisposition to obesity: a challenging but not insurmountable task. Am J Clin Nutr. 2010;91(1):5-6.

106. Audrain-McGovern J, Benowitz NL. Cigarette Smoking, Nicotine, and Body Weight. Clin Pharmacol Ther. 2011;90(1):164-168.

107. Aubin HJ, Farley A, Lycett D, et al. Weight gain in smokers after quitting cigarettes: meta-analysis. BMJ. 2012;345:e4439.

108. Tian J, Venn A, Otahal P, et al. The association between quitting smoking and weight gain: a systemic review and meta-analysis of prospective cohort studies. Obes Rev. 2015;16(10):883-901.

109. Mattes R, Foster GD. Food environment and obesity. Obesity (Silver Spring). 2014;22(12):2459-2461.

110. Wansink B. Environmental factors that increase the food intake and consumption values of unknowing consumers. Ann Rev Nutr. 2004;24:455-479.

111. Levine BE. Synergy of nature and nurture in the development of childhood obesity. Int J of Obesity. 2009;33(suppl 1):S53-S56.

112. Arcury TA, Trejo G, Suerken CK, et al. Housing and neighbourhood characteristics and Latino farm worker family well- being. J Immigr Minor Health. 2015;17(5):1458-1467.

113. Cleland V, Timperio A, Salmon J, et al. A longitudinal study of the family physical activity environment and physical activity among youth. Am J Health Promot. 2011;25(3):159-167.

114. Dajun D. Racial/ethnic and socioeconomic disparities in urban green space accessibility: Where to intervene? Landscape and Urban Planning. 2011;102(4):234-244.

115. Beets MW, Cardinal BJ, Alderman BL. Parental social support and the physical activity-related behaviors of youth: a Review. Health Educ Behav. 2010;37(5):621-644. 
116. Kraak VI, Story M, Wartella EA. Government and School Progres to Promote a Healthful Diet to American Children and Adolescents: A comprehensive review of the available evidence. Am J Prev Med. 2012;42(3):250-262.

117. Moellering DR, Smith DL. Ambient Temperature and Obesity. Curr Obes Rep. 2012;1(1):26-34.

118. Johnson F, Mavrogianni A, Ucci M, et al. Could increased time spent in a thermal comfort zone contribute to population increases in obesity? $J$ Obes Rev. 2011;12(7):543-551.

119. Bernhard MC, Li P, Allison DB, et al. Warm Ambient Temperature Decreases Food Intake in a Simulated Office Setting: A Pilot Randomized Controlled Trial. Front Nutr. 2015;2:20.

120. Alviola PA, Nayga RM, Thomson M. Food Deserts and Childhood Obesity. Appl Econ Perspect Pol. 2013;35(1):106-124.

121. Ghosh-Dastidar B, Cohen D, Hunter G, et al. Distance to Store, Food Prices and Obesity in Urban Food Deserts. Am J Prev Med. 2014;47(5):587-595.

122. Chamorro-Garcia R, Blumberg B. Transgenerational effects of obesogens and the obesity epidemic: a review. Curr Opin Pharmacol. 2014;19:153-158.

123. Grun F, Blumberg B. Minireview: The case for Obesogens. Mol Endocrinol. 2009;23(8):1127-1134.

124. Ghavamzadeh S, Khalkhali HR, Alizadeh M. Television (TV) Viewing, Independent of Physical Activity and Obesogenic Foods, Increases Overweight and Obesity in Adolescents. J Health Popul Nutr. 2013;31(3):334-342.

125. Janssen IM, Homan J, Schijns W, et al. Subclinical hypothyroidism and its relation to obesity in patients before and after Roux-en-Y gastric bypass. Surg Obes Relat Dis. 2015;11(6):1257-1263.

126. Young J, Zarcone J, Holsen L, et al. A measure of food seeking in individuals with Prader Willie syndrome. J Intellect Disabil Res. 2006;50(Pt 1):18-24.

127. Anderson AD, Solórzano CM, McCartney CR. Childhood obesity and its impact on the development of Adolescent PCOS. Semin Reprod Med. 2014;32(3):202-213.

128. Motta AB. The role of obesity in the development of polycystic ovary syndrome. Curr Pharm Des. 2012;18(17):2482-2491.

129. Sam S. Obesity and Polycystic Ovary Syndrome. Obes Manag. 2007;3(2):69-73.

130. Abraham SB, Abel BS, Rubino D, et al. A direct comparison of quality of life in obese and Cushing's syndrome patients. Eur J Endocrinol. 2013;168(5):787-793.

131. Weaver JU. Classical endocrine diseases causing obesity. Front Horm Res. 2008;36:212-228.

132. Hryhorczuk C, Sharma S, Fulton SE. Metabolic disturbances connecting obesity and depression. Front Neurosci. 2013;7:177.

133. Luppino FS, de Wit LM, Bouvy PF, et al. Overweight, Obesity, and Depression: Systematic Review and Meta-analysis of Longitudinal Studies. Arch Gen Psychiatry. 2010;67(3):220-229.

134. Simon GE, Von Korff M, Saunders K, et al. Association Between Obesity and Psychiatric Disorders in the US Adult Population. Arch Gen Psychiatry. 2006;63(7):824-830.

135. Holt R, Peveler R. Obesity, Serious Mental Illness and Antipsychotic Drugs. Diabetes Obes Metab. 2009;11(7):665-679.
136. McIntyre RS, McElroy SL, Konarski JZ, et al. Substance Use Disorders and Overweight/Obesity in Bipolar Disorder: Preliminary Evidence for Competing Addictions. J Clin Psychiatry. 2007;68(9):1352-1357.

137. Ahima RS, Antwi DA. Brain regulation of appetite and satiety. Endocrinol Metab Clin North Am. 2008;37(4):811-823.

138. Hege MA, Stingl KT, Kullmann S, et al. Attentional impulsivity in binge eating disorder modulates response inhibition performance and frontal brain networks. Int J Obes (Lond). 2015;39(2):353-360.

139. Volkow ND, Wang GJ, Baler RD. Reward, dopamine and the control of food intake: implications for obesity. Trends Cogn Sci. 2011;15(1):3746 .

140. Karlsson HK, Tuominen L, Tuulari JT, et al. Obesity Associated with Decreased $\mu$-Opioid but Unaltered Dopamine D2 Receptor Availability in the Brain. The Journal of Neuroscience. 2015;35(9):3959-3965.

141. Aguirre-Castaneda RL, Kumar S, Voigt RG, et al Childhood AttentionDeficit/Hyperactivity Disorder, Sex, and Obesity. A Longitudinal Population-Based Study. Mayo Clinic Proc. 2016;91(3):352-361.

142. Leslie WS, Hankey CR, Lean MEJ. Weight gain as an adverse effect of some commonly prescribed drugs: a systematic review. QJM. 2007;100(7):395-404.

143. Widen EM, Whyatt RM, Hoepner LA, et al. Excessive gestational weight gain is associated with long-term body fat and weight retention at $7 \mathrm{y}$ postpartum in African American and Dominican mothers with underweight, normal, and overweight pre-pregnancy BMI. Am J Clin Nutr. 2015;102(6):1460-1467.

144. Ashley-Martin J, Woolcott C. Gestational weight gain and postpartum weight retention in a cohort of Nova Scotian women. Matern Child Health J. 2014;18(8):1927-1935.

145. Fraser A, Tilling K, Macdonald-Wallis C, et al. Associations of gestational weight gain with maternal body mass index, waist circumference and blood pressure measured 16y after pregnancy: the Avon Longitudinal Study of Parents and Children(ALSPAC). Am J Clin Nutr. 2011;93(6):1285-1292.

146. Gunderson EP. Childbearing and Obesity in Women: Weight Before, During, and After Pregnancy. Obstet Gynecol Clin North Am. 2009;36(2):317-332.

147. Ong KK, Northstone K, Wells JC, et al. Earlier Mother's Age at Menarche Predicts Rapid Infancy Growth and Childhood Obesity. PLoS Med. 2007;4(4):e132.

148. Newman AM. Obesity in Older Adults. The Online Journal of Issues in Nursing. 2009; 14(1):3.

149. Villareal DT, Apovian CM, Kushner RF, et al. Obesity in older adults: technical review and position statement of the American Society for Nutrition and NAASO, The Obesity Society. Am J Clin Nutr. 2005;82(5):923-934.

150. Cameron AJ, Zimmet PZ. Expanding evidence for the multiple dangers of epidemic abdominal obesity. Circulation. 2008;117(13):1624-1626.

151. Pou KM , Massaro JM, Hoffman U, et al. Patterns of Abdominal Fat Distribution: The Framingham Heart Study. Diabetes Care. 2009;32(3):481-485.

152. Chesi A, Grant SFA. The Genetics of Pediatric Obesity. Trends Endocrinol Metab. 2015;26(12):711-721.

153. Fall T, Ingelsson E. Genome-wide association studies of obesity and metabolic syndrome. Mol Cell Endocrinol. 2014;382(1):740-757.

154. Farooqui IS, O'Rahilly S. Genetics and obesity in humans. Endocrine Rev. 2006;27(7):710-718. 
155. Horgan GW, Stubbs J. Predicting basal metabolic rate in the obese is difficult. Eur J Clin Nutr. 2003;57(2):335-340.

156. Yau YH, Potenza MN. Stress and eating behaviors. Minerva Endocrinol. 2013;38(3):255-267.

157. Whitaker K, Young-Hyman D, Vernon M, et al. Maternal stress predicts post partum weight retention. Matern Child Health J. 2014;18(9):2209_ 2217.

158. Janssen I, Bacon E, Pickett W. Obesity and its relationship with occupational work injury in the Canadian workforce. $J$ Obes. 2011;2011:531403.

159. Brunner EJ, Chandola T, Marmot MG. Prospective effect of job strain on general and central obesity in the Whitehall II Study. Am J Epidemiol. 2007;165(7):828-837.

160. Harris JL, Pomeranz JL, Lobstein T, et al. A Crisis in the Marketplace: How Food Marketing Contributes to Childhood Obesity and What Can Be Done. Annu Rev Public Health. 2009;30:211-225.

161. Nestle M. Food marketing and childhood obesity: a matter of policy. New Engl J Med. 2006;354(24):2527-2529.

162. Seiders K, Petty RD. Obesity and the role of food marketing: A policy analysis of issues and remedies. $J$ Public Policy and Marketing. 2004;23(2):153-169.

163. Hirsh JM. Hidden calories of home cooking. The Huffington Post. 2009

164. Rosenberg M. 10 Hidden Reasons for US Obesity, Part One. 2012.

165. Rosenberg M. 10 Hidden Reasons for US Obesity, Part Two. 2012.

166. Wansink B, Painter JE, Lee YK. The office candy dish, proximity's influence on estimated and actual consumption. Int J Obesity (Lond). 2006;30(5):871-875.

167. Jessen J. Our Overweight World: The Men Who Made Us Fat. HighLight Health. 2014.

168. Renzaho AM. Fat, rich and beautiful: changing socio-cultural paradigms associated with obesity risk, nutritional status and refugee children from sub-Saharan Africa. Health Place. 2004;10(1):105-113.

169. Subramanian SV, Perkins JM, Özaltin E, et al. Weight of nations: a socioeconomic analysis of women in low- to middle-income countries. Am J Clin Nutr. 2011;93(2):413-421.

170. Caprio S, Daniels SR, Drewnowski A, et al. Influence of race, ethnicity, and culture on childhood obesity: implications for prevention and treatment, consensus statement of shaping America's health and the obesity society. Diabetes Care. 2008;31(11):2211-2221.

171. Moens E, Braet C, Bosmans G, et al. Unfavorable family characteristics and their associations with childhood obesity: a cross sectional study. Eur Eat Disord Rev. 2009;17(4):315-323.

172. Rhee K. Childhood overweight and the relationship between parent behaviors, parenting style and family functioning. The Annals of the American Academy of Political and Social Science. 2008;615(1):11-37.
173. Misra A, Ganda OP. Migration and its impact on adiposity and Type 2 Diabetes. Nutrition. 2007;23(9):696-708.

174. Wang S, Quan J, Kanaya AM, et al. Asian Americans and obesity in California: A protective effect of biculturalism. J Immigr Minor Health. 2011;13(2):276-283.

175. Rosas LG, Guendelman S, Harley K, et al. Factors associated with overweight and obesity among children of Mexican descent:Results of a binational study. J Immigr Minor Health. 2011;13(1):169-180.

176. Lindsay KL, Gibney ER, McAuliffe FM. Maternal nutrition among women from sub-Saharan Africa with a focus on Nigeria and potential implications for pregnancy outcomes among immigrant populations in developed countries. J Hum Nutr Diet. 2012;25(6):534-546.

177. Delavari M, Sønderlund AL, Mellor D, et al. Migration, Acculturation and Environment: Determinants of Obesity among Iranian Migrants in Australia. Int J Environ Res Public Health. 2015;12(2):1083-1098.

178. Delavari M, Sønderlund AL, Swinburn B, et al. Acculturation and obesity among migrant populations in high income countries-a systematic review. BMC Public Health. 2013;13(1):458.

179. Renzaho AM, Swinburn B, Burns C. Maintenance of traditional cultural orientation is associated with lower rates of obesity and sedentary behaviours among African migrant children to Australia. Int $J$ Obes (Lond). 2008;32(4):594-600.

180. Renzaho AM, Halliday JA, Mellor D, et al. The Healthy Migrant Families Initiative: Development of a culturally competent obesity prevention intervention for African migrants. BMC Public Health. 2015;15:272.

181. Singh M. Mood, food, and obesity. Front Psychol. 2014;5:925.

182. Reeves GM, Postolache TT, Snitker S. Childhood Obesity and Depression: Connection between these Growing Problems in Growing Children. Int J Child Health Hum Dev. 2008;1(2):103-114.

183. Franklin J, Denyer G, Steinbeck KS, et al. Obesity and risk of low self-esteem: a statewide survey of Australian children. Pediatrics. 2006;118(6):2481-2487.

184. Cornette R. The emotional impact of obesity on children. Worldviews Evid Based Nurs. 2008;5(3):136-141.

185. Austin SB, Haines J, Veugelers PJ. Body satisfaction and body weight: Gender differences and socio-demographic determinants. BMC Public Health. 2009;9:313.

186. Lu E, Dayalu R, Diop H, et al. Weight and Mental Health Status in Massachusetts, National Survey of Children's Health, 2007. Matern Child Health J. 2012;16(Suppl 2):S278-S286.

187. USDA, My Plate Food Guide: United States Department of Agriculture Choose My Plate.

188. DGA 2015-2020: US Department of Health and Human Services and US Department of Agriculture. 2015-2020 Dietary Guidelines for Americans. 8th ed.

189. Nutrition, Physical Activity and Obesity: Healthy People. 2020. 